\title{
An Assessment on Impact of COVID-19 Infection in a Gender Specific Manner
}

\author{
Himanshu Agrawal ${ }^{1}$ (D) Neeladrisingha Das ${ }^{1}$ (D) - Sandip Nathani ${ }^{1}$ (D) $\cdot$ Sarama Saha $^{2} \cdot$ Surendra Saini $^{1}$. \\ Sham S. Kakar ${ }^{3}$ (D) Partha Roy ${ }^{1}$ (D)
}

Accepted: 25 September 2020 / Published online: 7 October 2020

(C) Springer Science+Business Media, LLC, part of Springer Nature 2020

\begin{abstract}
Coronavirus disease 2019 (COVID-19) is caused by novel coronavirus Severe acute respiratory syndrome coronavirus 2 (SARSCoV-2). It was first time reported in December 2019 in Wuhan, China and thereafter quickly spread across the globe. Till September 19, 2020, COVID-19 has spread to 216 countries and territories. Severe infection of SARS-CoV-2 cause extreme increase in inflammatory chemokines and cytokines that may lead to multi-organ damage and respiratory failure. Currently, no specific treatment and authorized vaccines are available for its treatment. Renin angiotensin system holds a promising role in human physiological system specifically in regulation of blood pressure and electrolyte and fluid balance. SARS-CoV-2 interacts with Renin angiotensin system by utilizing angiotensin-converting enzyme 2 (ACE2) as a receptor for its cellular entry. This interaction hampers the protective action of ACE2 in the cells and causes injuries to organs due to persistent angiotensin II (AngII) level. Patients with certain comorbidities like hypertension, diabetes, and cardiovascular disease are under the high risk of COVID-19 infection and mortality. Moreover, evidence obtained from several reports also suggests higher susceptibility of male patients for COVID-19 mortality and other acute viral infections compared to females. Analysis of severe acute respiratory syndrome coronavirus (SARS) and Middle East respiratory syndrome coronavirus (MERS) epidemiological data also indicate a gender-based preference in disease consequences. The current review addresses the possible mechanisms responsible for higher COVID-19 mortality among male patients. The major underlying aspects that was looked into includes smoking, genetic factors, and the impact of reproductive hormones on immune systems and inflammatory responses. Detailed investigations of this gender disparity could provide insight into the development of patient tailored therapeutic approach which would be helpful in improving the poor outcomes of COVID-19.
\end{abstract}

This article belongs to the Special Issue on COVID-19 Pandemic and

Stem Cells

Guest Editor: Mariusz Z. Ratajczak

Electronic supplementary material The online version of this article (https://doi.org/10.1007/s12015-020-10048-z) contains supplementary material, which is available to authorized users.

Partha Roy

partha.roy@bt.iitr.ac.in

Himanshu Agrawal

himanshu.bt@sric.iitr.ac.in

Neeladrisingha Das

ndas@bt.iitr.ac.in

Sandip Nathani

snathani@bt.iitr.ac.in

Sarama Saha

sarama.bchem@aiimsrishikesh.edu.in
Surendra Saini

sursaini123@gmail.com

Sham S. Kakar

sham.kakar@louisville.edu

1 Molecular Endocrinology Laboratory, Department of Biotechnology, Indian Institute of Technology Roorkee, Roorkee, Uttarakhand 247667, India

2 Department of Biochemistry, All India Institute of Medical Sciences, Rishikesh, India

3 Department of Physiology, James Graham Brown Cancer Center, University of Louisville, Louisville, KY 40292, USA 
Keywords Severe acute respiratory syndrome (SARS) $\cdot$ Coronavirus- $2 \cdot$ Spike protein $\cdot$ COVID-19 $\cdot$ Transmembrane protease serine- $2 \cdot$ Gender $\cdot$ Mesenchymal stem cells

\section{Introduction}

COVID-19 is caused due to recently emerged SARS-CoV-2 virus, tremendously affecting health and economy throughout the globe. In December 2019, first case of COVID-19 was documented in the Wuhan, China [1]. On January 30, 2020, World health organization (WHO) declared COVID-19 as public health emergency and since then, this disease has spread quickly to 216 countries and territories. According to world health organization (WHO), the basic reproduction rate (R0), which is defined as the probable secondary cases for each infected individual, is in the range of 2.0 to 2.5 [2]. However, this number seems to decrease progressively due to the employment of several epidemiological management approaches in many countries. To date (September 19, 2020), globally 30,295,744 persons are infected from this disease and unfortunately, a significant number of patients $(947,933)$ have died as a result of COVID-19 infection. United States of America (USA), India and Brazil are the top three severely affected countries with respect to number of infected patients. India although started late but with gradual spread of pandemic, the number of affected individuals has increased dramatically. Out of 30,295,744 cases, the number of cases confined in the USA, India and Brazil is $6,613,737,5,308,014$ and 4,455,386 respectively. In India on September 19,2020, a total of 85,619 deaths were reported that gives an apparent fatality rate of $1.61 \%$. For USA and Brazil, the fatality rate is 2.97 and 3.02 respectively. According to this index, India is less affected as compared to USA and Brazil [3].

Coronavirus $(\mathrm{CoV})$ has been distributed into the four genera named as $\alpha-/ \beta-/ \gamma-/ \delta-\mathrm{CoV}$. $\alpha$ - and $\beta-\mathrm{CoV}$ are known to infect the mammals; conversely $\gamma$-and $\delta$-CoV infects the birds. The SARS-CoV, SARS-CoV-2, and MERS-CoV are $\beta$-coronavirus. Like other members of CoVs (SARS-CoV and MERS-CoV), the transmission of SARS-CoV-2 also occur from human to human. Exposure to any of these viruses can cause a severe damage to various organs and fatal infection of the respiratory tract. Genome sequencing revealed a close association of SARS-CoV-2 with the Bat-CoV-RaTG13. SARSCoV-2 genome has 50, 79 and $96.2 \%$ similarity with MERS$\mathrm{CoV}$, SARS-CoV and Bat-CoV-RaTG13 respectively [4].

Recently, Liu et al. [5] detected the $\mathrm{CoV}$ in pangolin (Pangolin-CoV) and analyzed its sequence. They found $\sim 90 \%$ genome similarity of Pangolin-CoV with both the viruses (SARS-CoV-2 and Bat-CoV-RaTG13). Considering genome sequencing and evolutionary analysis, these authors suggest bat as a natural host for SARS-CoV-2 and proposed SARS-CoV-2 transmission to human came from bat via intermediate host pangolins (Fig. 1) $[4,5]$.
The renin-angiotensin system plays an important role in human physiology by regulating blood pressure and electrolyte fluid homeostasis. Renin-angiotensin system activation enhances the level of vasoconstrictor peptide Ang-II. Both SARS-CoV and SARS-CoV-2 interact with the reninangiotensin system through ACE2 receptor present on cell membrane. ACE2 negatively regulates the renin-angiotensin system activation through degrading Ang-II into vasodilator Ang-1-7 [6]. Thus, ACE2 acts as a defensive protein under various disease conditions such as hypertension, diabetes, and cardiovascular. The patients with these comorbidities come under the high-risk category of SARS-CoV-2 infection and possess a significantly higher mortality rate compared to patients without these comorbidities. Interaction of ACE2 with SARS viruses is considered as a major factor responsible for their massive pathogenicity [7].

In addition, available data also suggest a higher susceptibility of male patients for COVID-19 compared to females. For example, in China, the COVID-19 death rate in men is $4.7 \%$ compared to $2.8 \%$ in women. Similarly, in Italy, it is $16.6 \%$ in men compared to $9.1 \%$ in women [8]. Several pieces of evidences obtained from different clinical reports also confirmed higher respiratory infection in males compared to females including several acute viral infections [9]. In the present report, we addressed the possible underlying mechanisms associated with COVID-19 mortality predisposition towards males. In the first part, we described the mechanism of viral entry into cells followed by interaction with the reninangiotensin system. In the next part, we covered different underlying aspects such as smoking, impact of steroid hormones on immune system, genetic factors, expression of pro-inflammatory cytokines, and various treatment options. Recognition of COVID-19 mortality predisposition towards males will be helpful in considering the impact of the emergency approach on health and socio-economic aspects at individual and community levels.

\section{Mechanism of Virus Entry into Cells and Clinical Symptoms}

Similar to SARS-CoV, spike (S) protein of SARS-CoV-2 binds to ACE2 but with a 10 to 20 -fold higher affinity, thus enhancing the pathogenicity of SARS-CoV-2. Virus entry into the host cell also requires priming of $\mathrm{S}$ protein by host cell transmembrane serine protease 2 (TMPRSS2). Both these events lead to entry of SARS-CoV-2 into the host cells [10]. SARS-CoV-2 structure and mechanism of cell entry and 
Fig. 1 Possible transmission route of SARS-CoV-2 from bat to human
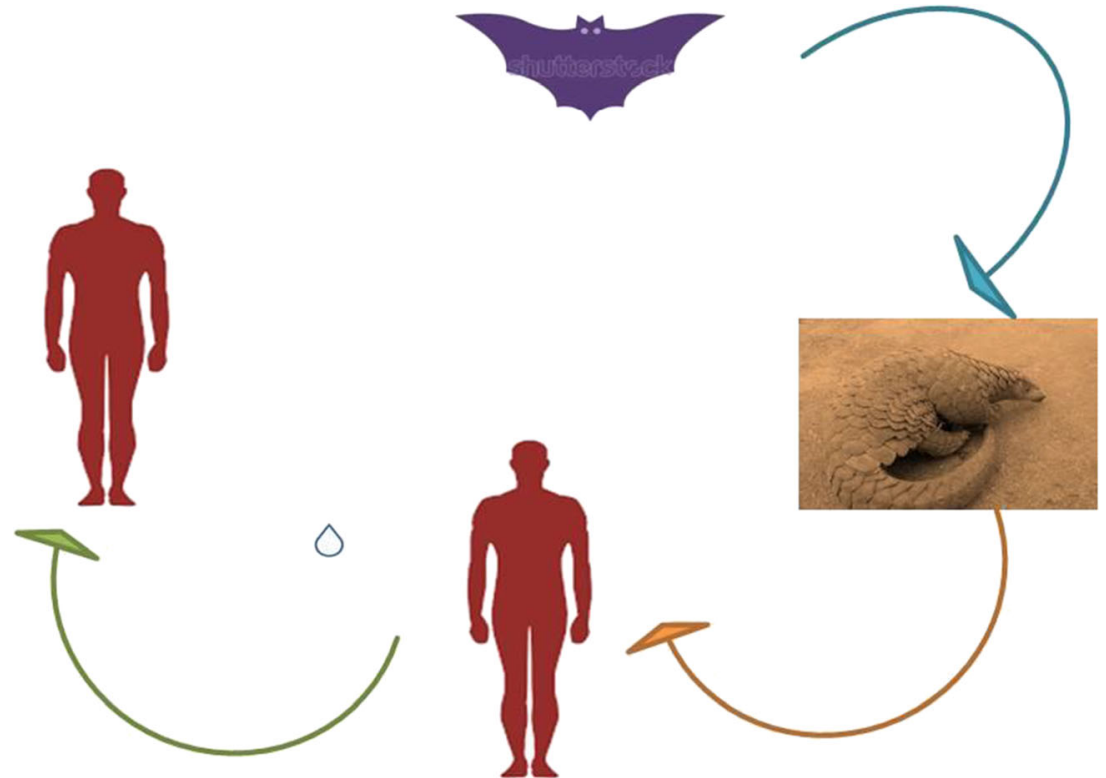

replication is depicted in Fig. 2. The prime target of SARSCoV-2 is the respiratory tract. Probably virus crosses the nasal and laryngeal mucosa, attack the pneumocytes and its dissemination leads to the infection of other organs that locally express the ACE2 including kidney, heart, and gastrointestinal tract [11]. The clinical features of COVID-19 patients exist in a wide range that includes asymptomatic state to acute respiratory distress syndrome and multi-organ dysfunction. The common clinical symptoms include fever, headache, sore throat, and breathlessness. In a few patients, the disease can progress to pneumonia followed by acute respiratory distress syndrome and requires admission to intensive care unit for mechanical ventilation [12].

Immune responses play a vital role in COVID-19 advancement and resolution. Interaction of virus with host cells develops a varied range of immune mediators to protect the body against invading SARS-CoV-2. This exaggerated immune reaction in certain cases can cause damage to host organs [13]. Progression to multi-organ failure in these patients is closely associated with an extremely increased plasma level of inflammatory chemokines and cytokines termed as cytokine release syndrome. The cytokine storm is remarkably associated with the critical condition of COVID-19 patients as evident from clinical studies [14, 15]. Radiological findings of COVID-19 pneumonia patients clearly indicate a strong inflammatory response in the lower respiratory tract leading to pulmonary damage [16]. Mallick et al. [17] reported broncho alveolar stem cells as important target for SARS$\mathrm{CoV}$ infection. Hence, the hypothetical explanation of the rapid deterioration and delay in recovery of COVID-19 pneumonia cases may be due to destruction of lung stem cells along with pneumocytes by the novel corona virus, SARACoV-2 [18, 19].

\section{Interaction of SARS-CoV-2 with Renin-Angiotensin System}

Renin-Angiotensin System holds a vital role in human physiology specifically in the regulation of blood pressure, electrolyte, and water balance. Renin-angiotensin system pathway produces different bioactive compounds in a sequential manner. Angiotensinogen is synthesized and released by the liver and cleaved by renin secreted from the juxtaglomerular cells of the kidney into decapeptide angiotensin I (Ang-I). Ang-I is further hydrolyzed by angiotensin-converting enzyme (ACE) into AngII. Ang-II is the key molecule of the renin-angiotensin system and exerts its effect through binding to angiotensin type 1 (AT1) and type 2 (AT2) receptors [6, 20]. Binding of Ang-II to AT1 and AT2 mediates the exact opposite effects. Activation of AT1 mediates the detrimental effects such as vasoconstriction, aldosterone secretion, inflammation, fibrosis, and oxidative stress. Conversely, AT2 activation has protective effects such as antiinflammatory, anti-fibrotic, and release of vasodilators. ACE2, another important enzyme of the renin-angiotensin system regulates the level of Ang-II by cleaving it into heptapeptide, Ang-17. Ang-1-7 mediates its effects through binding with the Mas receptor and counteracts the deleterious effects of ACE/Ang-II/ AT1 axis [21]. Thus, ACE and ACE2 regulate blood pressure homeostasis in the cardiovascular system by maintaining the balance between Ang-II and Ang-1-7. Renin-angiotensin system is involved in both SARS-CoV and SARS-CoV-2 infections as these viruses enter into the cell through binding with ACE2 receptor present on the membrane. The physiological expression of ACE2 determines the level of infectivity of these viruses by regulating the entry of virus and renin-angiotensin system activation. Thus, ACE2 could be considered as a promising target for controlling the severity of SARS-CoV-2 infection [22]. 
a

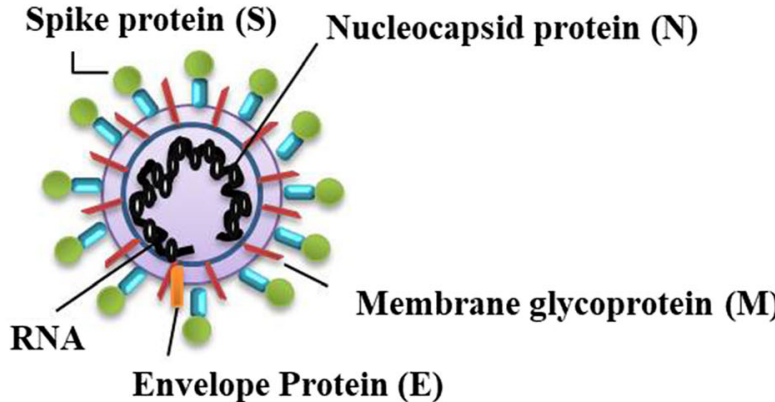

Envelope Protein (E)

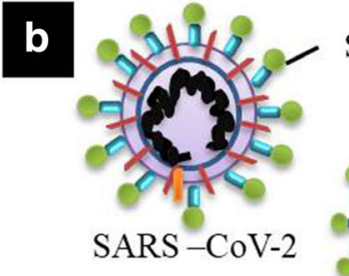

Spike glycoprotein proteolytic cleavage
As of 19-09-2020

Disease name- COVID19

Emergence-December 2019

Total cases- $30,295,744$

Total death- 947,933

Countries and territories affected- 216
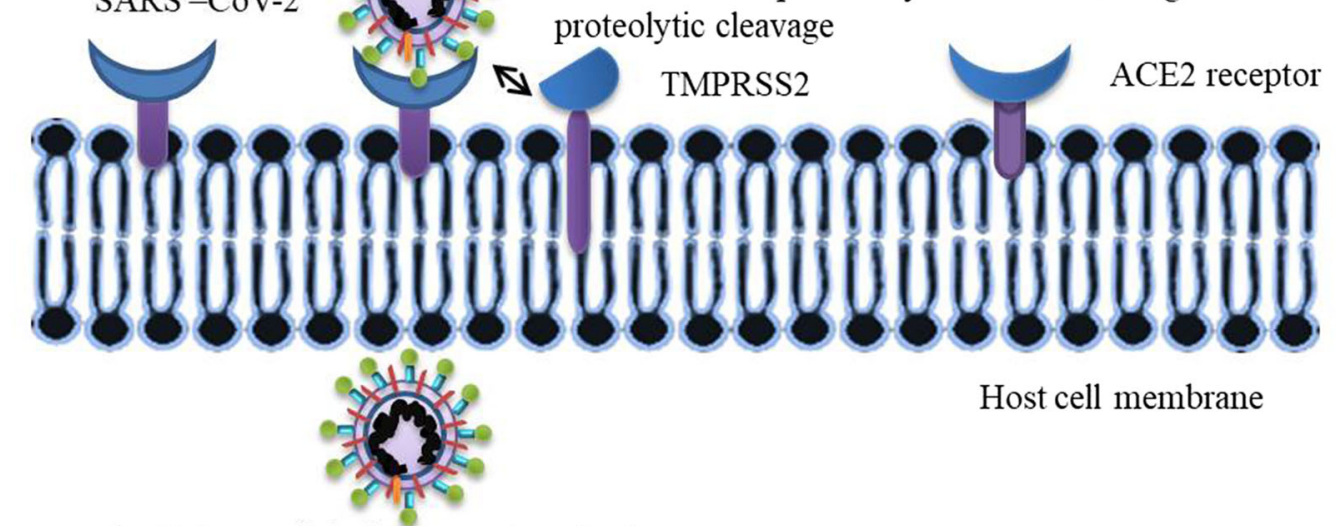

Attachment of SARS-CoV-2 to ACE2

Activation of S protein by TMPRSS2 through

Host cell membrane

$\checkmark$ Release of viral genome in cytoplasm

$\checkmark \quad$ Translation of viral polyprotein ppla and pplab

$\checkmark$ Genomic RNA replication and transcription

\section{Infection}

$\checkmark$ Translation of viral structural protein (S, M and E) on ER and nucleocapsid protein in cytoplasm

$\checkmark \quad \mathrm{S}, \mathrm{E}$ and $\mathrm{M}$ protein combine with nucleocapsid protein at ER golgi intermediate compartment

$\checkmark$ Assembly of new virion
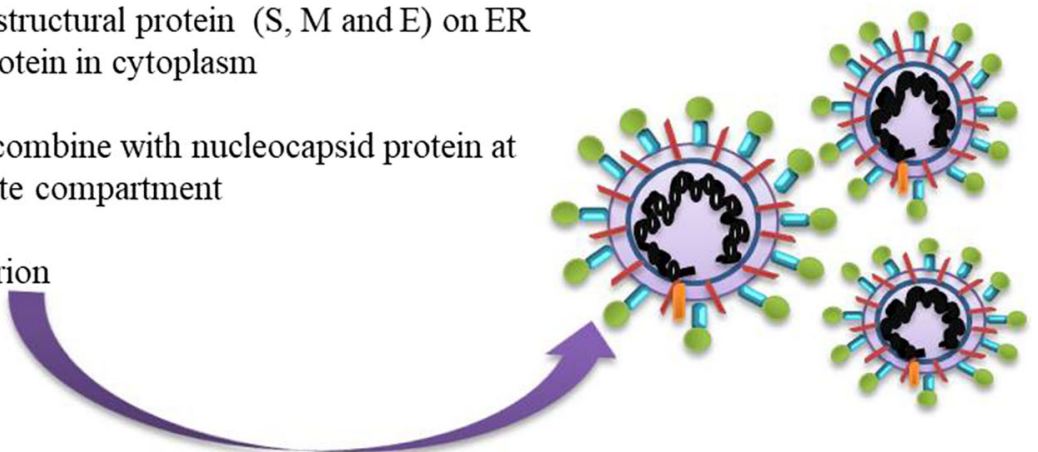

Fig. 2 (a) Structure of SARS-CoV-2; (b) Mechanism of virus entry into cells and its mode of replication. Adopted from Jiang et al. (2020) [153]

SARS-CoV and SARS-CoV-2 not only use the ACE2 for cell entry, but it also causes the downregulation of ACE2 on cell surface thus attenuate its protective actions in cells [23, 24]. In vitro studies suggest that sustained infection and replication of coronavirus in cells causes the suppression of ACE2 level at the plasma membrane (Fig. 3) [25]. In a mouse model, acute lung injury occurred due to the exposure to SARS-CoV S protein which was then suppressed after the renin-angiotensin system was blocked [23]. Downregulation of ACE2 in response to bacterial endotoxin also leads to acute Ang-II accumulation and 


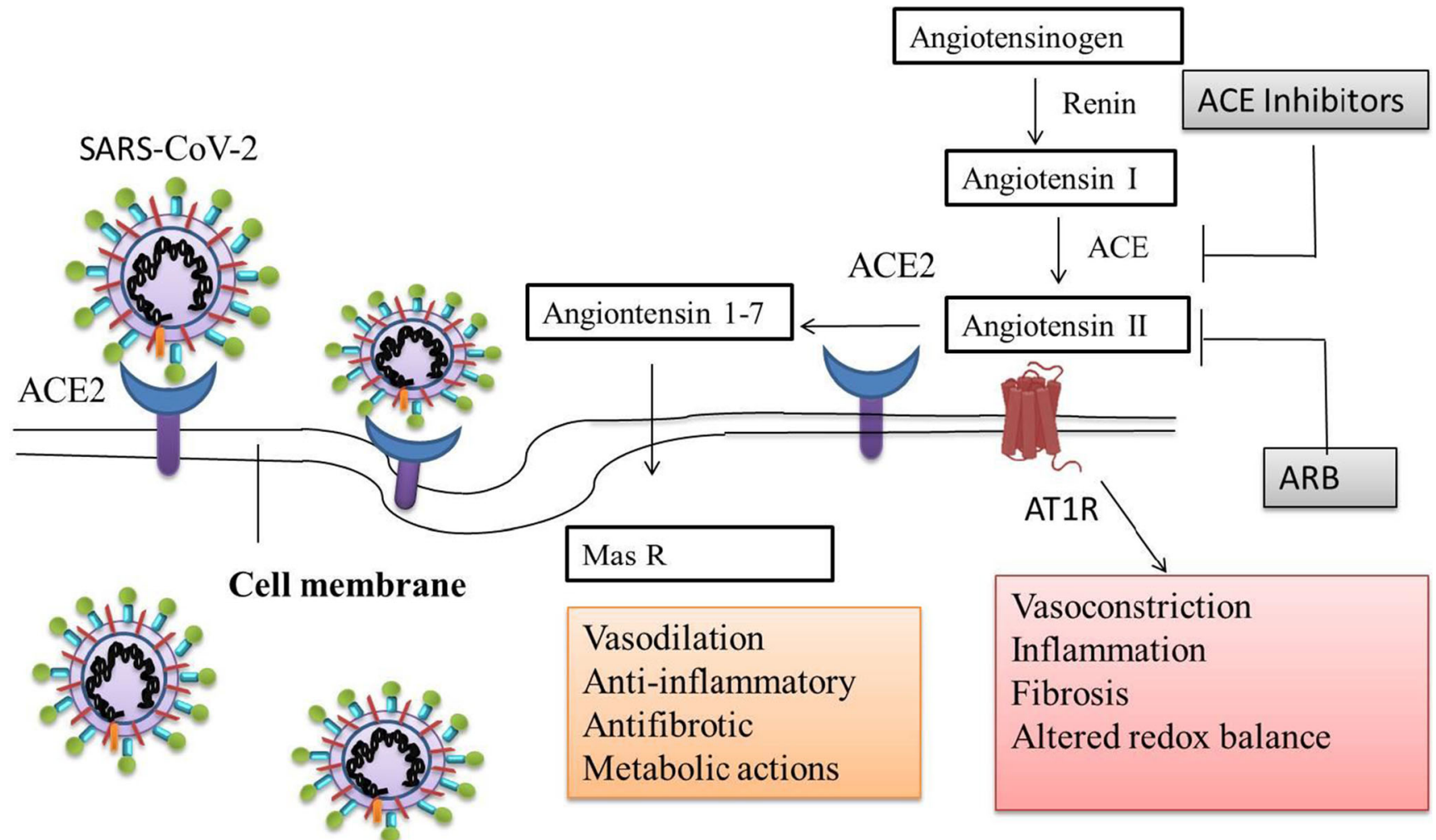

SARS-CoV2 enter into cell and replicate itself and caused the downregulation of ACE2

Fig. 3 RAS system and its interaction with SARS-CoV-2. Adopted from Vaduganathan et al. 2020 [6]

renin-angiotensin system activation and thus causing lung injury [26]. Thus, it can be speculated but need to be confirmed that, persistently high level of Ang-II due to downregulation of ACE2 might be accountable for organ injuries during SARS-CoV-2 infections.

On the other hand, some preclinical studies also raised the concern about the safety of renin-angiotensin system inhibitors for patients with comorbidities such as diabetes mellitus, hypertension, cerebrovascular and cardiovascular disorders that require these inhibitors frequently to control the pre-existing conditions, since elevated ACE2 expression in response to renin-angiotensin system inhibitors, would make them vulnerable for COVID-19 or worsen the present condition [6]. In order to confirm such observations, clinical trials are underway to examine the usefulness and safety of losartan, an Angiotensin II receptor blocker (ARB) in COVID-19 infected patients. In this respect, medical professionals suggest continuation of renin-angiotensin system inhibitors in the high-risk patients as sudden withdrawal may cause detrimental health consequences and lead to clinical instability $[6,7,27]$.

\section{Impact of Gender on COVID-19 Outcome}

Global data suggests that SARS-CoV-2 infection did not show an inclination towards men versus women. In most countries, it is reasonably similar whereas in some countries, it is higher in men compared to women. In spite of this inconclusive information, the available data provides differences in severity and death rate in men versus women. For example, among the confirmed cases in China, the infection rate is equal but the death rate in men is $4.7 \%$ as compared to $2.8 \%$ in women. Similarly, in Italy, it is $16.6 \%$ in men versus $9.1 \%$ in women [8]. The Global health 50/50 provided sex-segregated data of SARS-CoV2 infection and death rate for the severely affected countries. Few countries including Brazil, India, USA, UK, and Russia have not reported data related to sex-segregation [28]. We calculated the death ratio (male: female) based on case fatality rate using the data provided by global health 50/50. The data from 33 countries, showed death ratio value in the range of 2.8-1.4 which is depicted in Table 1. Most of the studies deal with a few speculations regarding the influence of gender on severity of COVID-19 infection. In order to have a holistic insight into this information, a detailed and thorough literature review was carried out using the available literature sets so as to propose a probable gender specific impact of this infection. After proper validation of such information a cost effective and sex-customized therapeutic protocol could be generated to provide a promising outcome for the cure and management of COVID-19. 


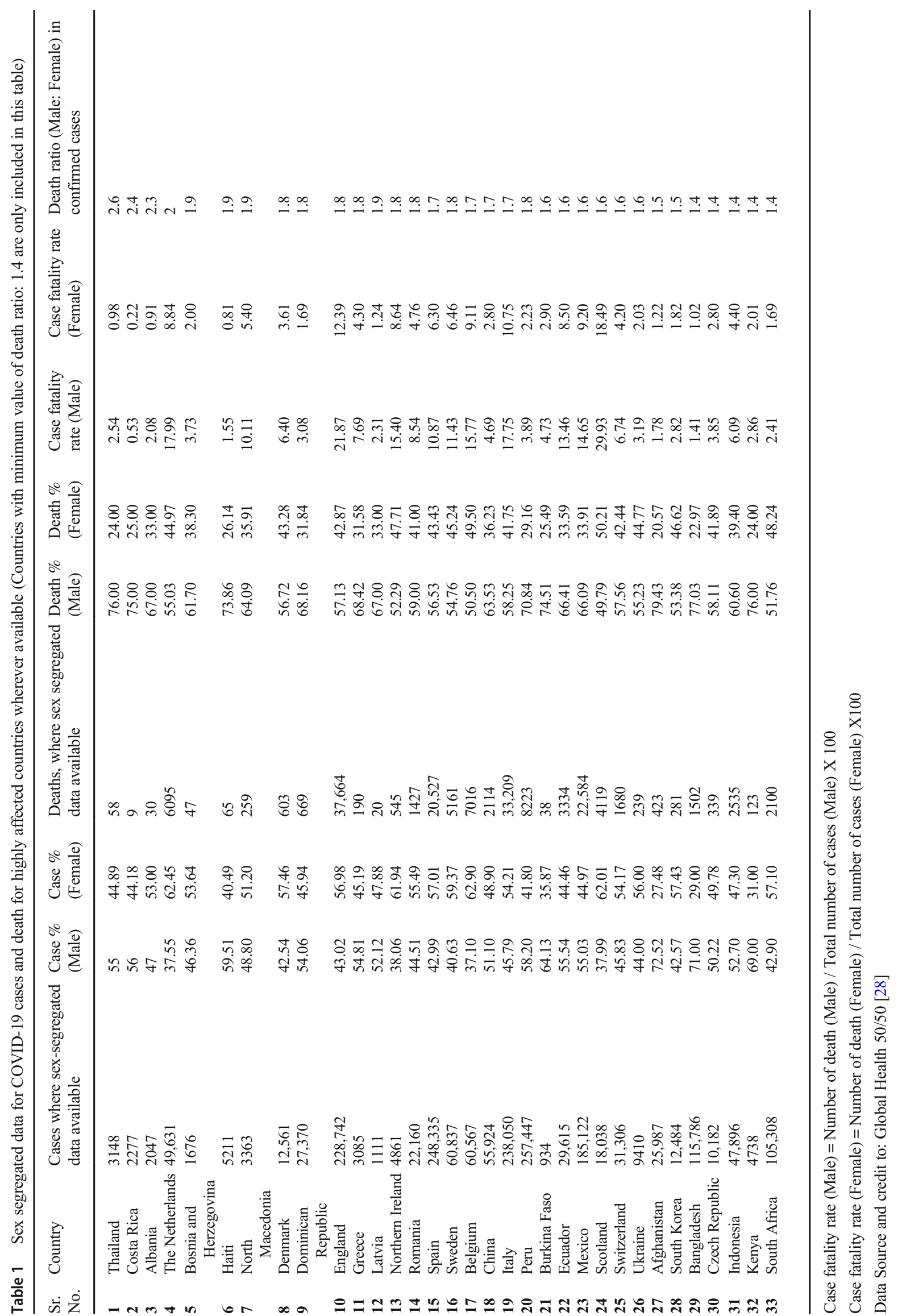




\section{Probable Factors Responsible for Higher Mortality Rate among Males Due to COVID-19 Infection}

Data obtained from different countries provide a tentative basis responsible for sex-based difference in mortality caused by COVID-19 infection (Fig. 4). In the following section, we highlighted the possible causes that could be linked to such differences.

\section{Higher Smoking Rate in Male and its Association with COVID-19 Severity}

Enormous evidences support the association of smoking with different disease prognosis. The use of tobacco adversely affects lung fitness and makes the individual vulnerable to several respiratory system-related diseases [29]. The smoking has also been reported to hamper immune responses against infectious pathogens and thus making individuals more susceptible to different infectious diseases [30]. Acute respiratory tract infections (ARTI) are majorly caused due to viruses (70$80 \%$ ) that includes influenza, coronavirus, rhinovirus and respiratory syncytial virus [31]. Several evidences suggested an increased risk of infection and recurrence of viral infections in upper respiratory tract among smokers as compared to nonsmokers [32-34]. Smoking is also found to suppress the protective action of influenza vaccine and increased the morbidity of influenza [33]. Previous evidences also suggested more likelihood of smokers being infected with influenza and with severe suffering as compared to non-smokers [35]. According to a report, active smokers were found to be about 7-times more predisposed to death risk by influenza [36]. Similarly, during the MERS outbreak, smokers were reported with higher mortality as compared to non-smokers [37]. ACE2 is known as a principle regulatory molecule of renin angiotensin system and contributes significantly in kidney, heart and gastrointestinal tract physiology. These organs are proven target sites for SARS-CoV-2 infection. Binding of SARS-CoV-2 with ACE2 facilitates its entry into the host cells. Thus, upregulation of ACE2 activity or expression may enhance the vulnerability of SARS-CoV-2 infection and severity of this disease. Recently, Smith et al. [38] analyzed the expression of ACE2 in human and mice lung tissue using the single-cell sequencing. Alteration in ACE2 expression was analyzed in various epithelial cells lining of the respiratory tract in response to smoking. These authors demonstrated that the secretary cells of the respiratory tract express ACE2. Expression of ACE2 was found to be higher in cigarette smoking individuals compared to non-smokers, and withdrawal of smoking suppressed the ACE2 expression and number of secretory cells. Therefore, these results actually establish some of the probable reasons which might
Fig. 4 Possible reasons which may be responsible for high mortality rate in males infected with COVID-19

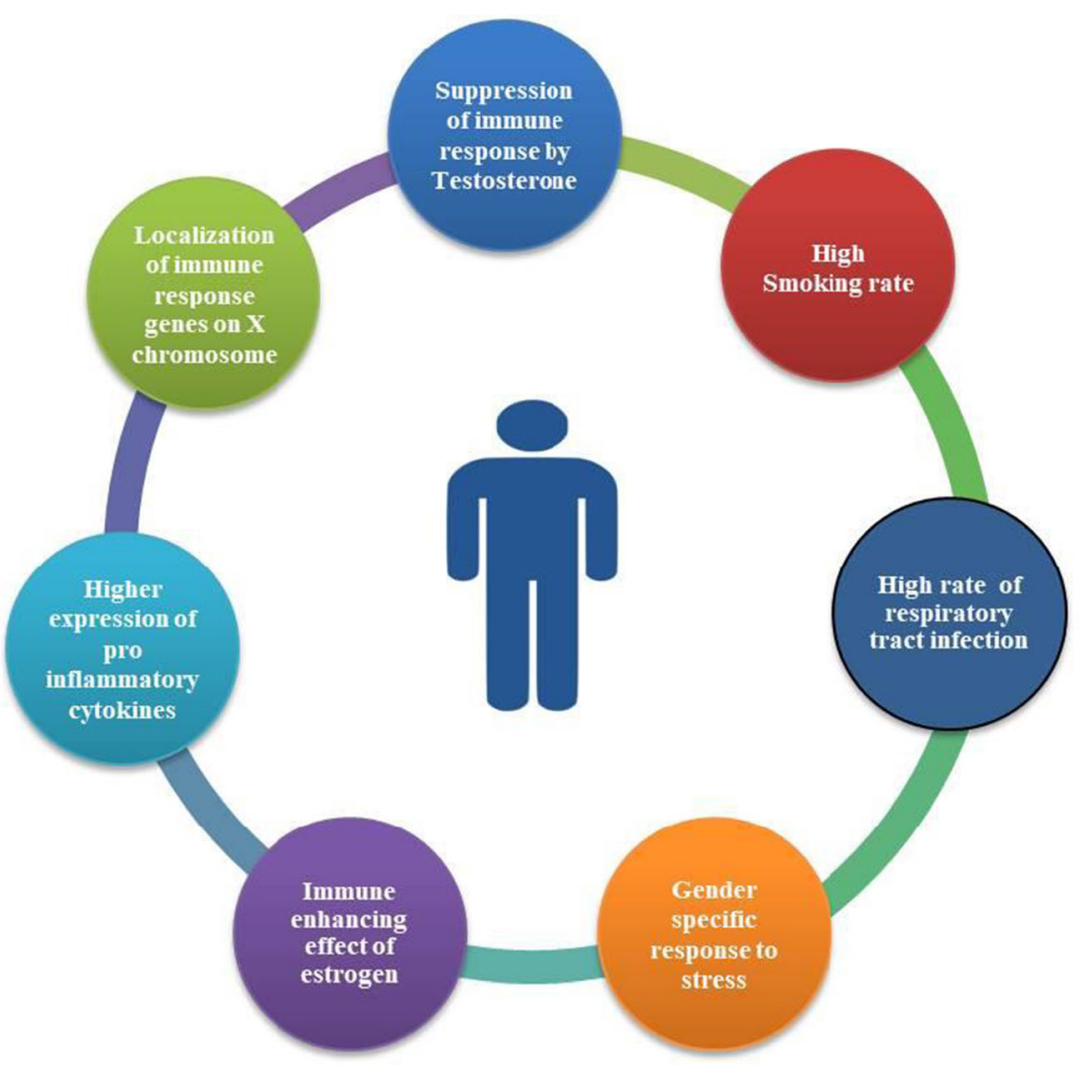


responsible for enhanced susceptibility of smokers towards SARS-CoV-2 infection.

Some recent studies also provided valuable information about the relationship of COVID-19 and smoking. These studies takes into account of COVID-19 associated severity like the requirement of mechanical ventilation and admission in an intensive care unit and death. Tobacco smokers not only have higher tendencies $[\sim 1.4$ fold (Relative risk $(\mathrm{RR})=1.4$, 95\% CI: 0.98-2.00)] to develop COVID-19 severity but also have a higher fatality rate (2.4-fold higher) as compared to non-smokers. The need for mechanical ventilation and ICU admission was also more (2.4-fold) in smokers $[39,40]$ compared to non-smokers. Thus, based on these facts, it could be speculated that higher level of ACE2 in the lung of smokers could be a major reason responsible for severe consequences and special care requirement.

A close association in COVID-19 death rate and comorbidities for hypertension, diabetes, lung, and cardiovascular diseases has also been established. These comorbid conditions are allied with certain lifestyle behaviors including smoking and alcohol consumption that are quite higher in men particularly in Asian and African countries compared to women [29]. Further, to confirm a relationship between smoking and the COVID-19 death rate, we checked the smoking rate data from different countries. Globally smoking rate is extremely high in men (35\%) as compared to women $(6 \%)$ [41]. A higher smoking rate among male population is frequently found in underdeveloped and developing countries. Conversely, the smoking rate among both the genders is almost equal in developed countries. The detail of smoking rate in major countries belonging to all 6 subcontinents is provided in Table 2 [41]. Together, these data indicate a higher inclination of males towards COVID-19 infections and smoking could be one of the contributing factors for it. In order to establish strong correlation in this aspect there is need of accumulation of data from large number of cases from different ethnic groups indicating a relationship between COVID-19, smoking, and ACE2 expressions.

\section{High Rate of Respiratory Tract Infection in Male}

At present, the majority of health problems in humans are significantly led by respiratory viral infections [42]. The prevalence and consequences of different inflammatory lung diseases including viral infections is found to be sex dependent in humans. Information sought from various clinical reports across globe suggests a higher rate of respiratory infections in males as compared to females, including acute viral infections [43]. As a first line of defense, immunity of individual initially prevents the entry of viruses followed by promoting antigen-specific adaptive immune response for tissue repairing. Recently, many studies have highlighted marked sex-based differences in innate immunity pathways during viral infections [44]. The cells that participate in innate and adaptive immunity express steroid hormone receptors as well. Modulation in these receptors or levels of steroid hormones exhibited that the activity of these receptors is sex-dependent with respect to the number of immune cells and their functional response in the respiratory tract. In respiratory tract, steroid hormones initiate and promote anti-viral immune response by interacting with cellular signaling pathways [45].

Three classes of sex-dependent steroid hormones are available, namely androgens, estrogen, and progesterone [46]. In plasma, testosterone levels (male sex hormone) remain constant till the age of 30 and afterward it starts to decline to some extent with progression of age [47] While in female, due to existence of menstrual cycle, levels of sex hormones fluctuate regularly and with the onset of menopause, sex hormones levels drop further [48]. Therefore, both branches (innate and adaptive) of the immune response in human contribute in sexual dimorphism [49].

\section{Immune Suppressive Effect of Testosterone}

As far as correlation of testosterone and immunity is concerned, testosterone has been reported to play a pleiotropic role i.e. immunosuppressive $[50,51]$ and anti-inflammatory $[52,53]$. In blood about $30 \%$ of lymphocytes are present and among them $80-90 \%$ are T lymphocytes. The population of T lymphocytes is further divided into T-helper, T-cytotoxic and $\mathrm{T}$-suppressor cells [54]. In view of the gender-based immune response, researchers have determined the blood cell counts during the various phases of reproductive stages. Studies on numbers and sub-sets of $\mathrm{T}$ cell receptor-expressing lymphocytes have shown that total number of lymphocytes is almost equal in males and females but percentage of $\mathrm{T}$ lymphocytes among total number of lymphocytes in males is less as compared to females [55]. These facts have been justified by increased apoptosis of $\mathrm{T}$ cells due to a higher level of testosterone in males [56]. In case of females, studies have shown that subtypes and total number of lymphocytes remain unaltered during menstrual cycle thus indicating that the number of lymphocytes is not affected by estrogen or progesterone [56]. Different studies have reported a general pattern of suppressed immunity in males due to presence of testosterone $[57,58]$. This action of testosterone leads to lower adaptive immunity due to suppressed function of associated type $2 \mathrm{~T}$ helper cells and type $17 \mathrm{~T}$-helper cells, and hence decreased antibody responses and B cell proliferation $[59,60]$. In seriously ill COVID-19 patients, these conditions attributed to delayed antibody response, along with lower production of effective $\mathrm{IgG}$, in men as compared to women which could be associated with worse prognosis [61]. In vitro study has shown that testosterone decreases or inhibits the production of interleukin (IL)-4, IL-10 and IL-13 in dendritic cells which act as antigen presenting cells in humoral immunity. Besides this, 
Table 2 Differences in smoking rate in men and women in various sub-continents across the globe

\begin{tabular}{|c|c|c|c|}
\hline Continent/Countries & Smokers (Male \%) & Smokers (Female \%) & Male: Female ratio \\
\hline Globally & 35 & 6 & 5.8 \\
\hline \multicolumn{4}{|l|}{ Africa } \\
\hline South Africa & 33.2 & 8 & 4.2 \\
\hline Tunisia & 65.8 & 1.1 & 59.8 \\
\hline Egypt & 50.1 & 0.2 & 250.5 \\
\hline Ethiopia & 8.5 & 0.4 & 21.3 \\
\hline Uganda & 16.7 & 3.4 & 4.9 \\
\hline Liberia & 18.1 & 1.5 & 12 \\
\hline Morocco & 47.1 & 0.8 & 58.9 \\
\hline Nigeria & 10.8 & 0.6 & 18 \\
\hline \multicolumn{4}{|l|}{ Asia } \\
\hline China & 48.4 & 1.9 & 25.5 \\
\hline Indonesia & 76.1 & 2.8 & 27.2 \\
\hline Turkey & 41.1 & 14.1 & 2.9 \\
\hline India & 20.6 & 1.9 & 10.8 \\
\hline Vietnam & 45.9 & 1.0 & 45.9 \\
\hline Japan & 33.7 & 11.2 & 3.0 \\
\hline Bangladesh & 44.7 & 1.0 & 44.7 \\
\hline Malaysia & 42.4 & 1.1 & 38.5 \\
\hline Pakistan & 36.7 & 2.8 & 13.1 \\
\hline \multicolumn{4}{|l|}{ South America } \\
\hline Chile & 41.5 & 34.2 & 1.2 \\
\hline Brazil & 17.9 & 10.1 & 1.8 \\
\hline Columbia & 13.5 & 4.7 & 2.9 \\
\hline Ecuador & 12.3 & 2 & 6.2 \\
\hline \multicolumn{4}{|l|}{ North America } \\
\hline United Sates & 24.6 & 19.1 & 1.3 \\
\hline Mexico & 21.4 & 6.9 & 3.1 \\
\hline Columbia & 13.5 & 4.7 & 2.9 \\
\hline Canada & 16.6 & 12 & 1.4 \\
\hline \multicolumn{4}{|l|}{ Europe } \\
\hline Poland & 33 & 23 & 1.4 \\
\hline Netherland & 27.3 & 24.4 & 1.1 \\
\hline Ireland & 25.7 & 23 & 1.1 \\
\hline Slovania & 25 & 20.1 & 1.2 \\
\hline Germany & 33.1 & 28.2 & 1.2 \\
\hline Spain & 31.4 & 27.4 & 1.1 \\
\hline Austria & 30.9 & 28.4 & 1.1 \\
\hline Sweden & 18.9 & 18.8 & 1.0 \\
\hline Greece & 52 & 35.3 & 1.5 \\
\hline \multicolumn{4}{|l|}{ Oceania } \\
\hline Australia & 16.5 & 13 & 1.3 \\
\hline New Zeeland & 17.2 & 14.8 & 1.2 \\
\hline Fiji & 34.8 & 10.2 & 3.4 \\
\hline
\end{tabular}

Data source and credit to: Hannah R and Max R (2013) (Reference No. 41)

Male: Female ratio $=$ Percentage of male smokers/percentage of female smokers it also down-regulates the expression of major histocompatibility complex class II (MHC-II) receptors in antigen- presenting cells $[59,62]$. However, this suppressive effect of testosterone has been contradicted in in vivo studies where 
testosterone was found to enhance the production of antiinflammatory cytokines [59]. Previous human and rodent studies have also shown that testosterone downregulates the pro-inflammatory cytokines (IL-6, IL-1 $\beta$ ) and tumor necrosis factor- alpha (TNF- $\alpha$ ) synthesis and augments the production of anti-inflammatory cytokine IL-10 [63, 64]. Furthermore, a recent study reported that testosterone attenuates inflammatory immune response by inhibiting type $17 \mathrm{~T}$-helper cells and promoting the differentiation of regulatory T-cells [65].

Age and other medical complications are the major factors for the change in testosterone level in men. Series of evidences suggest that the testosterone level decreases in males at a rate of $0.4-2 \%$ per year starting from the age of 30 years $[47,66]$. This may lead to a situation of hypogonadism among elderly males with advancing age. The other major problem during the older age is the prevalence of associated comorbidities like- obesity, diabetes and other cardiac related issues [67]. A number of earlier reports substantiated a positive correlation between these comorbidities and lower testosterone level [68, 69]. Additionally, in elder and comorbid male patients, insufficient or reduced production of testosterone leads to enhanced systemic inflammation [64]. Hence, it can be speculated that elderly males and associated comorbidities may have reduced anti-inflammatory cytokines as compared to healthy young men.

Additionally, investigations have indicated that aging men with suppressed testosterone level have elevated proinflammatory markers involving IL-6, TNF- $\alpha$ and IL- $1 \beta$ [70]. As per a recent clinical report from Hamburg, Germany, majority of male patients infected with COVID19 had lower testosterone level [71]. Moreover, from the case studies on the deceased population during COVID-19, median age of the deceased population was found to be $\geq 65$ years and majority of the cases are male $[72,73]$. All these factors provide a basis to assume that there are possibilities of higher production of pro-inflammatory cytokines in males under specified circumstance which in turn predispose them more towards COVID-19 infection.

Recent studies also provide an important fact about the androgen-dependent expression of TMPRSS2. During the SARS-CoV-2 infection, priming of spike protein through TMPRSS2 is a crucial step. In human, the promoter of TMPRSS2 gene possesses a 15 base pair androgen response element (ARE). It is expected that the expression of TMPRSS2 is dependent upon androgen receptor binding to these response elements. To date no other promoter for TMPRSS2 has been identified in humans [74]. TMPRSS2 expression was found to increase steadily in presence of androgen in prostate cancer and lung epithelial cell lines [75, 76]. In males, higher expression of androgen could lead to enhanced expression of TMPRSS2 and it might be a possible reason for higher susceptibility of males for COVID-19 infection [77]. Besides participating in SARS-CoV2 infection,
TMPRSS2 mediate key function in proteolytic activation of some other influenza and coronaviruses [78]. Enhanced expression of TMPRSS2 in male is closely associated with increased susceptibility towards SARS-CoV [79], MERS-CoV [80], Asian H7H9 influenza A virus [81] and 2009 pandemic H1N1 influenza A virus infection [82]. Therefore, testosterone mediated TMPRSS2 modulation might be suggested as a crucial factor for male prevalence in these infections [78]. However, till to date, no study has been conducted to examine the impact of anti-androgen therapy in COVID-19 patients. Interestingly, anti-malarial drug hydroxychloroquine which is being used for the COVID-19 treatment, and its analog chloroquine phosphate, is found to suppress the secretion of testosterone in albino rats [83]. This information warrants further studies to decipher a direct link between the level of testosterone and the effect of anti-viral drugs.

\section{Immune Enhancing Effect of Estrogen}

Generally, estrogen is considered as an immune-enhancing steroid hormone in females [84]. It exerts its response by interfering with negative selection of auto-reactive B cells and leads to $\mathrm{T}$ helper cells' response in adaptive immunity [85, 86]. Apart from reproductive tissues, estrogen receptors (ERs) are found to be present in the brain, gut epithelial cells, lymphoid tissue cells, and various immune cell populations, including monocytes, macrophages and lymphocytes [87, 88]. As far as ERs are concerned, reports have shown that estrogen receptor-alpha (ER- $\alpha)$ is substantially expressed in all immune cells and is mainly responsible for their regulation and maturation [89]. ER has been reported to participate in regulation of signaling events of innate immune cells and thus contribute significantly in sex-specific immune responses [90].

Series of evidences have demonstrated that estradiol promotes synthesis of type 1 interferon after binding to ER- $\alpha[90$, 91]. Probably, ER- $\alpha$ promotes type 1 interferon synthesis either by positively regulating its direct expression or by increasing the expression of genes involved in innate stimuli sensing pathways. Indeed, accumulating evidence from murine splenocytes shows that estradiol promotes the type I interferon-inducible innate pathways and expression of genes involved such as Aim2, p202, Unc93b1, Aim2, Baff and Irf5 [92-94]. Consistent with this observation, the same authors also showed that interferon regulating genes are highly expressed in females at baseline as well as after interferon stimulation [92-94]. These facts confirm a positive correlation between ER $\alpha$ and interferon-1 and their regulatory aspects in innate immunity. From the gender disparity perspective, a body of work shows over-expression of ER- $\alpha$ in female in comparison to the male $[95,96]$.

Estrogen enhances expression of C-C chemokine receptor type 5 (CCR5) in $\mathrm{T}$ cells and induces adhesion of circulating 
lymphocytes in blood to specialized endothelial cells $[87,88]$. Estrogen has also been shown to affect adaptive immunity by inducing IL-4 production that leads to differentiation of type $2 \mathrm{~T}$ helper cells [97]. Another study in mice states that estrogen increases differentiation of $\mathrm{T}$ helper type 1 cells and suppresses differentiation of type $17 \mathrm{~T}$-helper cells and decreases the level of interlukin-17 (IL-17) cytokine [98]. These findings suggest that estrogen ultimately promotes antibody synthesis by stimulating the $\mathrm{B}$ cells differentiation which boosts immune system in females. Additionally, various studies in human and rodent models established the fact that estrogen at physiologically higher concentration inhibits the synthesis of various pro-inflammatory cytokines including IL-6, IL- $1 \beta$ and TNF- $\alpha$ and chemokine (C-C motif) ligand 2 (CCL2) from monocyte and macrophage and thereby obstruct the migration of neutrophil and monocyte into the inflamed areas (a crucial factor in progression of COVID-19 associated cytokine storm) [99]. In COVID-19 severely ill patients, a significantly higher level of IL-6 has been observed as compared to moderately ill patients. Apart from this, postmortem examination of lungs of COVID-19 patient revealed extreme infiltration of proinflammatory cells that majorly involves macrophage and $\mathrm{T}$ helper cells [100]. In accordance with this fact, SARS Co-V experiment in murine model also showed a remarkable role of sex hormones in corona virus pathogenesis as enhanced accumulation of inflammatory monocyte macrophage was observed in the lungs of age-matched male mice when compared to female infected mice. Additionally, gonadectomized female mice showed a remarkably increase in mortality $(85 \%)$ compared to control female mice (20\%) [101]. Based on these facts it can be hypothesized that excess estrogen signaling in female could protect them from cytokine storm through suppressing the synthesis of pro-inflammatory molecules and limiting the migration of monocyte and neutrophil cells to lungs. Thus, a balanced immune response in females may provide a better protection against SARS-CoV-2 infection as compared to males.

\section{Localization of Immune Response Genes on X Chromosome}

Another major factor for hyper-responsiveness of female immunity is the presence of a double $\mathrm{X}$ chromosome. Genetically, X chromosomes possess many genes responsible for immunity e.g. CD40 ligand (CD40L), Forkhead box P3 (FOXP3), Toll-like receptor 8 (TLR 8) and Toll-like receptor 7 (TLR 7) [102, 103]. In the context of gender disparity, it can be speculated that any sort of mutations affecting the genes responsible for immunity and related pathways may alter the immunological responses and signaling pathways in males and females. There is a chance of a double dosage of proteins associated with $\mathrm{X}$ chromosomes in females. To avoid this situation, one $\mathrm{X}$-chromosome is silenced randomly during
$\mathrm{X}$-chromosome inactivation, a routine event in female embryogenesis $[104,105]$ and provides an advantage against deleterious X-linked mutations and confers extra diversity in different biological and immune responses. However, it is quite evident that, exceptionally, some genes of $\mathrm{X}$ chromosomes may escape silencing [106]. For instances, an escape in the immune or related genes, the females have an elevated level of immune genes due to biallelic expression. This phenomenon has a dual impact on female physiology. In case of the immune cells, the biallelic expression of X-linked genes may either promote harmful inflammatory or autoimmune responses or it can be useful in providing enhanced immunity [103-107]. TLR-7 is one such protein responsible for pathogen recognition and activation of innate immunity. It is encoded on X-chromosome and mainly expressed in monocytes, plasmacytoid dendritic cells (pDC), and B-cells [108, 109]. In case of escape from $X$-chromosome silencing, the biallelic expression of TLR-7 results in the overexpression of same in females than males [110]. This may be another reason for the immunity advantage in females over males, therefore may provide protective advantage against COVID19 infection or death. However, these predictions need to be tested further before making a conclusive assessment.

\section{Higher Expression of pro-Inflammatory Cytokines in Male}

During viral load to the cells, innate immune cells such as lymphocytes and monocytes are stimulated to produce interferon- $\alpha$ which is an important inflammatory cytokine of the immune system. However, COVID-19 infected cells are traced by activated natural killer (NK) cells and are then killed by induced inflammation [111, 112]. In specific immunity, viral loads stimulate plasma cells and B lymphocytes to produce immunoglobulin $\mathrm{G}$ (IgG) antibodies. Substantial increase in $\operatorname{IgG}$ then leads to their subsequent recognition by CD16 receptor of killer cells. This results in the destruction of virus with consequent enhancement of pro-inflammatory cytokines [13, 15]. Analysis of broncho alveolar lavage fluid of COVID-19 patients showed a higher level of various proinflammatory cytokines like TNF $\alpha$, IL-6, IL-1 and accumulation of chemokines including CCL2, CCL3, chemokine (C-XC motif) ligand 10 (CXCL10) and CXCL8 [113]. The excess release of these pro-inflammatory cytokines cause acute inflammation of the surrounding tissues and may result in patient death due to cytokine storm [114]. Recent studies demonstrate that a significant population of COVID-19 patients experience cytokine storms [115]. Evidence shows that males are more prone for the enhanced production of proinflammatory cytokines as compared to females [116]. IL-6 is one of the major pro-inflammatory cytokines and along with IL-7, IL-17 and IL-18 participate in the generation of cytokine storm. According to a recent clinical study by Wei et al. [117], 
IL6ST (receptor of IL-6), IL-7, IL-16, and IL-18 are expressed to a remarkably higher levels in men compared to women. Certain chemokines like CCL3, CCL4 and CXCL16 have a protective effect against viral infections [118]. Conversely, lower expression of protective chemokines like CCL2, CCL3, CCL4, and CXCL16 was observed in male COVID19 patients than female patients [117]. These observations could partially explain the underlying reasons that probably predispose males to higher risk of COVID-19 severity as compared to females.

\section{Gender Specific Response to Stress}

A proper response to acute stress is the fundamental for adaptation. The cross talk between hypothalmo-pituitary adrenal (HPA) axis and sympathoadrenal system play an important role in survival from acute stress [119]. Pandemic restriction and isolation by quarantine during COVID-19 are acting as sources of stress [120]. Cumulating evidence suggest that gender based response to stress probably results from differential modulation of HPA axis by sex hormones [121]. Both clinical as well as experimental models reported that exposure to stress in initial life enhance the risk of development of psychosocial disorders in males [122]. A stronger adrenocorticotropic hormone (ACTH) response following exposure to stress was observed in female experimental animals compared to male animals [123].

In order to develop complete active matured lineages of neuroendocrine stress system, both endogenously and exogenously derived stress would differentiate the stem cells as well as progenitor cells [124]. It is observed that stress can modulate the number of stem cells in adrenal glands [125]. Grabek et al. [126] documented that the differentiation of stem cells of adult adrenal cortex was quicker in females as compared to males. Thus gender-specific difference in response to the stress system could be one speculative justification for increased mortality in male COVID-19 patients [18] compared to female.

\section{SARS and MERS Outcomes Represent a Similar Pattern}

Data obtained from SARS (2002-2003) and MERS (2012) also showed that disease outcomes are influenced by the patient's gender. SARS-CoV interacts with ACE2 and downregulates its activity. Suppression of ACE2 activity resulted in enhanced production of Ang-II by the counter enzyme i.e., ACE. Subsequently, the adverse effect of hyperactivation of AT1 leads to the development of lung pathology [127]. First known case of SARS was reported in the year 2002 in Foshan, China. Thereafter, the disease spread to Hong Kong and from there it spread to several other countries including Vietnam and Canada. According to WHO, a total of 8096 confirmed cases were reported in 27 countries with 774 deaths by July 2003 [128]. Afterward, the SARS pandemic was announced to be ended, with no further infections. Karlberg et al. [129] analyzed the SARS data of 1755 confirmed cases provided by the Department of Health, Hong Kong. A total of 299 deaths were recorded that gives an overall mortality rate of $17 \%$ (299/1755 X100). Similar to COVID-19 and MERS, male suffered from an enhanced fatality. Male patients had a considerably higher case fatality rate $(21.9 \%)$ compared to women $(13.2 \%)$. Previously Channappanavar et al. [101] examined the effect of sex on SARS-CoV infection susceptibility using a mouse model. To determine it, they infected different age groups of male and female mice with mouse adapted SARS-CoV (MA15). The mice were categorized in different age groups i.e. young (8-9 weeks), adult (5 months), and middle-aged (8-9 months). Their studies showed more susceptibility among male mice for SARS-CoV infection compared to age-matched female mice. SARS-CoV infection susceptibility is also influenced by age and more pronounced effect was evident in middleaged mice. Further the lungs from male mice showed greater viral titers, vascular leakage, and alveolar edema, extensive hyperemia, and congestion compared to female animals. Accumulation of neutrophils and inflammatory monocytemacrophage was also demonstrated in the lungs of male mice. Further, an interesting role of estrogen in the protection of female mice against SARS-CoV infection was also provided by this study. Treatment of female mice with an estrogen antagonist or performing ovariectomy augmented the mortality in female mice. Thus, the result of this study confirmed a positive function of estrogen signaling against SARS-CoV pathogenesis and highlighted the sex-based predisposition of SARS CoV infection.

Similar to other CoVs, MERS-CoV infection also caused severe respiratory distress and failure of the renal system. MERS outbreak occurred in the year 2012 and most primary cases confined to Middle East countries specifically in Saudi Arabia (73\%), and some secondary cases were reported in 27 other countries. The clinical symptoms of MERS showed a higher resemblance with COVID-19 symptoms, though a higher mortality rate was observed in the case of the former (35\%). In a study, Alghamdi et al. [130] analyzed 422 MERS cases documented through health ministry of the Saudi Arab in the period of June 6, 2013, and May 14, 2014. It was found that $62 \%$ of cases (260 cases) were limited to males and $38 \%$ (162 cases) to the female population. The death rate of MERS also showed a predisposition towards males. According to this report, case fatality rate in males was significantly high $(52 \%)$ as compared to women (23\%). Outside of Arab Peninsula, South Korea experienced the largest outbreak of MERS with 186 cases in 2015 [131]. In this occasion, 110 cases $(59.5 \%)$ were reported in males and 76 cases in females $(41.5 \%)$. A 
total of 33 patients (22 males and 11 females) could not survive. Thus, case fatality rate value in men and women was $20 \%$ and $15 \%$ respectively, and represents a marginal predisposition towards men. The overall mortality rate $(20.4 \%)$ was also lesser as compared to other reports (34-37\%).

\section{Current Therapies for COVID-19 Treatment}

To control COVID-19 spread, certain public health actions have proven to be helpful that include isolation, quarantine, and social distancing. Research is underway to identify the specific and effective treatment for COVID-19. Meanwhile, to treat COVID-19 patients, different broad-spectrum therapeutic methods are being applied.

\section{Anti-Viral Therapy}

At the current stage for therapeutic purpose no specific drug or vaccine is available to prevent or cure against COVID-19 infection. Certain anti-malarial drugs such as hydroxychloroquine and anti-viral drugs that include HIV protease inhibitor and nucleoside analogs are being used to diminish viral infections till the development of precise antiSARS-CoV-2 drugs or vaccine is available. Various therapies are being tested globally. Nevertheless, large randomized controlled trials are not performed to examine the exact effectiveness for any drug [132]. Hydroxychloroquine shows anti-viral property by affecting the proteolytic processing and acidification process in the endosomal compartment. Azithromycin is a proven macrolide antibiotic. Recently, Gautret et al. [133] used hydroxychloroquine and azithromycin in combination for COVID-19 treatment. They observed $100 \%$ recovery of COVID-19 patients with this combination therapy, whereas $57.1 \%$ recovery was observed in patients who received hydroxychloroquine alone. Remdesivir was widely used for Ebola treatment. It is an antiviral nucleoside analog and hampers the action of RNA dependent RNA polymerase activity of viruses. This drug showed a positive effect during animal studies conducted using the MERS and SARS [132]. Remdesivir obtained emergency use authorization (EUA) from the US Food and Drug Administration (FDA) and is being used in USA for hospitalized COVID-19 patients. It reduces the recovery time to 11 days and suppresses the mortality [134]. Some other pieces of evidences supporting its effectiveness for COVID-19 treatment have also been documented [135]. The lopinavir-ritonavir combination was also examined for its effectiveness in COVID-19 treatment. Lopinavir is used for HIV treatment and possesses antiprotease activity, whereas, ritonavir enhanced the plasma level of lopinavir by suppressing its cytochrome p450 3A mediated metabolism [132]. There was no significant difference in either viral clearance or mortality as revealed by a study involving 199 patients [136]. IL-6 and other cytokines are elevated in the blood of COVID-19 patients. IL-6 stimulates an inflammatory response in a cascade manner after binding to its soluble and membrane-bound receptors. Sarilumab and tocilizumab are the drugs that specifically inhibit the binding of IL-6 to its soluble and membrane-bound receptor respectively. These inhibitors are now being examined for their effectiveness for COVID-19 infection [137].

\section{Mesenchymal Stem Cells (MSCs) Therapy}

Mesenchymal stem cells (MSCs) are known to possess promising anti-inflammatory as well as immune-modulatory properties [138-140]. Various studies demonstrated that MSCs treatment could be useful in chronic lung injury and the acute respiratory distress syndrome conditions [141]. MSCs exert such effect due to their suppressing action on proinflammatory cytokine secretion and immune cell penetration to pulmonary tissue. MSCs are able to differentiate into alveolar cells but not get infected by SARS-CoV-2 since they do not express ACE2 receptor and TMPRSS2 enzyme. Thus, MSCs can localize in lungs and improve pulmonary function of COVID-19 patients with severely compromised lung condition. Additionally, MSCs treatment also protects lung tissue by promoting lung repair and preventing fibrosis. Therefore, along with anti-viral drugs, MSCs could be a potential treatment option for COVID-19 infected patients due to their protective action against lung injury induced by cytokine storm [142]. In addition, MSC treatment has shown its potential role in mice by considerably improving acute lung injury caused due to H9N2 avian influenza virus [143] and H5N1 [144]. In pig, it improved the acute lung injury that occurred during the influenza infection [145]. However, certain limitations are restricting its wide application that includes the supply of clinical-grade MSCs and their preparation for clinical purposes. These restrictions can be overcome by stem cell bank. In recent times, some countries have initiated clinical studies and few reports have also been published. Recently, in China, MSCs treatment was applied to a female patient suffering from acute COVID-19. Initially, she was treated with antiviral drugs but could not recover. Thereafter, she was treated with umbilical cord MSCs with three consecutive injections that resulted in her discharge from the ICU and recovery from many clinical symptoms [146]. Another study on MSCs transplantation was conducted in China on 7 patients in collaboration with United States. The result of this study showed significant improvement in clinical symptoms in all patients after the second day of transplantation [147]. Throughout the world, approximately 47 clinical trials on "mesenchymal stem cell therapy in COVID 19" patients have been registered in Clinical trial.gov in order to investigate the safety and efficacy of MSC therapy. In most of the trials, recruitment of study participants is going on and, in some cases, it is in the process 
to initiate the trials. Some of these clinical trials have been presented in the Supplementary Table 1. Combining this information on exacerbated expression of pro-inflammatory cytokines in males and immunomodulatory property of MSCs, it is proposed that MSCs could be a promising therapeutic approach for the management of severity in male COVID-19 infected patients.

\section{Convalescent Plasma Therapy}

Convalescent plasma therapy has been documented as successful treatment option against various infectious diseases like polio, chickenpox, SARS-CoV, H1N1 influenza, and MERS-CoV [132, 148, 149]. The collected plasma contains antibodies against the virus and can suppress viral replication, promote phagocytosis, and complement activation. This therapy offers immediate but short-term immunity to the patients. Convalescent plasma therapy is being used globally with variable accomplishment to treat COVID-19 infected patients due to unavailability of any specific treatment [150]. During SARS, use of convalescent plasma therapy also decreased the mortality rate [151]. Recently, Shen et al. [152] applied convalescent plasma therapy for five COVID-19 patients those required assistance of mechanical ventilation. The authors determined the positive role of convalescent plasma in recovery though patient received lopinavir/ritonavir antiviral therapy and interferon. Although various studies have stated the promising role of convalescent plasma therapy in COVID-19 patients, its actual impact has not been examined using randomized clinical trials.

\section{Conclusion}

It has been evident across different mammalian species ranging from rodents to humans that males and females respond differently to several viral infections. Prevalence and outcome of viral infections are also influenced by gender. It is found to be more prevalent in males compared to female. The underlying mechanism behind this difference is quite complex and involves several factors including behavioral, genetic, hormonal, and immunological factors. In accordance with this hypothesis, current data on COVID-19 mortality suggests a higher susceptibility among males as compared to females. The COVID-19 mortality is also significantly associated with certain comorbidities like diabetes, kidney disease, hypertension and cardiovascular disease. These conditions are closely associated with smoking and alcohol consumption which has higher association with males specifically in Asian and African countries. Other factors for this disparity in sexspecific COVID-19 outcomes might be sex hormones and certain X linked genes that influence both innate and adaptive immunity in responses to viral infection. Moreover, androgen- dependent TMPRSS2 expression may also explain the prevalence for COVID-19 among male population. Epidemiological data of SARS and MERS outcome also showed a higher prevalence among males. Similar to this, animal studies of SARS suggested more susceptibility of male mice towards SARS-CoV infection and confirmed the positive function of estrogen signaling against SARS-CoV pathogenesis. Since male patients showed a higher expression of pro-inflammatory cytokines and MSCs showed therapeutic potential through immunomodulation, treatment with MSCs along with conventional therapy may be considered especially for the treatment of critically ill male COVID-19 patients. Therefore, there is a need of analyzing this gender specific pathogenicity for SARS-CoV-2 infection on large population-based survey which will provide an in-detail insight in this aspect of infection. Detailed investigation of this gender disparity could be helpful in improving the poor outcomes of COVID-19 and public health strategies should consider these gender specific variations at the time of therapeutic treatments and prophylaxis recommendations.

Funding Part of this research was funded by NIH T32HL134644 (SSK).

\section{Compliance with Ethical Standards}

Conflict of Interest Authors declare that they have no conflict of interest.

\section{References}

1. Zhu, N., Zhang, D., Wang, W., Li, X., Yang, B., Song, J., Zhao, X., Huang, B., Shi, W., Lu, R., Niu, P., Zhan, F., Ma, X., Wang, D., Xu, W., Wu, G., Gao, G. F., Tan, W., \& China Novel Coronavirus Investigating and Research Team. (2020). A novel coronavirus from patients with pneumonia in China, 2019. The New England Journal of Medicine, 382(8), 727-733.

2. Report of the WHO-China Joint Mission on Coronavirus Disease 2019 (COVID-19) (2020). [Accessed June 8, 2020]: Available at: https://www.who.int/docs/default-source/coronaviruse/who-china-joint-mission-on-covid-19- final-report.pdf

3. WHO Coronavirus Disease (COVID-19) Dashboard. [Online]. Available at: https://covid19.who.int/ [Accessed on September 19, 2020].

4. Guo, Y. R., Cao, Q. D., Hong, Z. S., Tan, Y. Y., Chen, S. D., Jin, H. J., Tan, K. S., Wang, D. Y., \& Yan, Y. (2020). The origin, transmission and clinical therapies on coronavirus disease 2019 (COVID-19) outbreak - an update on the status. Military Medical Research, 7(1), 11.

5. Liu, P., Jiang, J. Z., Wan, X. F., Hua, Y., Li, L., Zhou, J., Wang, X., Hou, F., Chen, J., Zou, J., \& Chen, J. (2020). Are pangolins the intermediate host of the 2019 novel coronavirus (SARS-CoV-2)? PLoS Pathogens, 16(5), e1008421.

6. Vaduganathan, M., Vardeny, O., Michel, T., McMurray, J., Pfeffer, M. A., \& Solomon, S. D. (2020). Renin-angiotensinaldosterone system inhibitors in patients with Covid-19. The New England Journal of Medicine, 382(17), 1653-1659. 
7. Rossi, G. P., Sanga, V., \& Barton, M. (2020). Potential harmful effects of discontinuing ACE-inhibitors and ARBs in COVID-19 patients. ELife, 9, e57278.

8. Gagliardi, M. C., Tieri, P., Ortona, E., \& Ruggieri, A. (2020). ACE2 expression and sex disparity in COVID-19. Cell Death Discovery, 6, 37.

9. Elgendy, I. Y., \& Pepine, C. J. (2020). Why are women better protected from COVID-19: Clues for men? Sex and COVID-19. International Journal of Cardiology, S0167-5273(20)32693-0. Advance online publication.

10. Hoffmann, M., Kleine-Weber, H., Schroeder, S., Krüger, N., Herrler, T., Erichsen, S., Schiergens, T. S., Herrler, G., Wu, N. H., Nitsche, A., Müller, M. A., Drosten, C., \& Pöhlmann, S. (2020). SARS-CoV-2 cell entry depends on ACE2 and TMPRSS 2 and is blocked by a clinically proven protease inhibitor. Cell, 181(2), 271-280.e8.

11. Verdecchia, P., Cavallini, C., Spanevello, A., \& Angeli, F. (2020). The pivotal link between ACE2 deficiency and SARS-CoV-2 infection. European Journal of Internal Medicine, 76, 14-20.

12. Singhal, T. (2020). A review of coronavirus Disease-2019 (COVID-19). Indian Journal of Pediatrics, 87(4), 281-286.

13. Azkur, A. K., Akdis, M., Azkur, D., Sokolowska, M., van de Veen, W., Brüggen, M. C., O'Mahony, L., Gao, Y., Nadeau, K., \& Akdis, C. A. (2020). Immune response to SARS-CoV-2 and mechanisms of immunopathological changes in COVID-19. Allergy, 75(7), 1564-1581.

14. Pedersen, S. F., \& Ho, Y. C. (2020). SARS-CoV-2: A storm is raging. The Journal of Clinical Investigation, 130(5), 2202-2205.

15. Kadkhoda, K. (2020). COVID-19: An Immunopathological view. MSphere, 5(2), e00344-e00320.

16. Li, K., Wu, J., Wu, F., Guo, D., Chen, L., Fang, Z., \& Li, C. (2020). The clinical and chest CT features associated with severe and critical COVID-19 pneumonia. Investigative Radiology, 55(6), 327-331.

17. Mallick, B., Ghosh, Z., \& Chakrabarti, J. (2009). MicroRNome analysis unravels the molecular basis of SARS infection in bronchoalveolar stem cells. PLoS One, 4(11), e7837.

18. Steenblock, C., Todorov, V., Kanczkowski, W., Eisenhofer, G., Schedl, A., Wong, M. L., Licinio, J., Bauer, M., Young, A. H., Gainetdinov, R. R., \& Bornstein, S. R. (2020). Severe acute respiratory syndrome coronavirus 2 (SARS-CoV-2) and the neuroendocrine stress axis. Molecular Psychiatry, 25(8), 1611-1617.

19. Bornstein, S. R., Steenblock, C., Chrousos, G. P., Schally, A. V., Beuschlein, F., Kline, G., Krone, N. P., Licinio, J., Wong, M. L., Ullmann, E., Ruiz-Babot, G., Boehm, B. O., Behrens, A., Brennand, A., Santambrogio, A., Berger, I., Werdermann, M., Sancho, R., Linkermann, A., Lenders, J. W., Eisenhofer, G., \& Andoniadou, C. L. (2019). Stress-inducible-stem cells: A new view on endocrine, metabolic and mental disease? Molecular Psychiatry, 24(1), 2-9.

20. Rahimi, Z., Moradi, M., \& Nasri, H. (2014). A systematic review of the role of renin angiotensin aldosterone system genes in diabetes mellitus, diabetic retinopathy and diabetic neuropathy. Journal of research in medical sciences: the official journal of Isfahan University of Medical Sciences, 19(11), 1090-1098.

21. Malha, L., Mueller, F. B., Pecker, M. S., Mann, S. J., August, P., \& Feig, P. U. (2020). COVID-19 and the renin-angiotensin system. Kidney International Reports, 5(5), 563-565 Advance online publication

22. D'Ardes, D., Boccatonda, A., Rossi, I., Guagnano, M. T., Santilli, F., Cipollone, F., \& Bucci, M. (2020). COVID-19 and RAS: Unravelling an unclear relationship. International Journal of Molecular Sciences, 21(8), 3003-3010.

23. Kuba, K., Imai, Y., Rao, S., Gao, H., Guo, F., Guan, B., Huan, Y., Yang, P., Zhang, Y., Deng, W., Bao, L., Zhang, B., Liu, G., Wang, Z., Chappell, M., Liu, Y., Zheng, D., Leibbrandt, A.,
Wada, T., Slutsky, A. S., Liu, D., Qin, C., Jiang, C., \& Penninger, J. M. (2005). A crucial role of angiotensin converting enzyme 2 (ACE2) in SARS coronavirus-induced lung injury. Nature Medicine, 11(8), 875-879.

24. Gheblawi, M., Wang, K., Viveiros, A., Nguyen, Q., Zhong, J. C., Turner, A. J., Raizada, M. K., Grant, M. B., \& Oudit, G. Y. (2020). Angiotensin-converting enzyme 2: SARS-CoV-2 receptor and regulator of the renin-angiotensin system: Celebrating the 20th anniversary of the discovery of ACE2. Circulation research, 126(10), 1456-1474.Injury. Nature Medicine, 11(8), 875-879.

25. Dijkman, R., Jebbink, M. F., Deijs, M., Milewska, A., Pyrc, K., Buelow, E., van der Bijl, A., \& van der Hoek, L. (2012). Replication-dependent downregulation of cellular angiotensinconverting enzyme 2 protein expression by human coronavirus NL63. The Journal of General Virology, 93(Pt 9), 1924-1929.

26. Sodhi, C. P., Wohlford-Lenane, C., Yamaguchi, Y., Prindle, T., Fulton, W. B., Wang, S., McCray Jr., P. B., Chappell, M., Hackam, D. J., \& Jia, H. (2018). Attenuation of pulmonary ACE2 activity impairs inactivation of des-Arg 9 bradykinin/ BKB1R axis and facilitates LPS-induced neutrophil infiltration. American Journal of Physiology Lung Cellular and Molecular Physiology, 314(1), L17-L31.

27. Liu, M. Y., Zheng, B., Zhang, Y., \& Li, J. P. (2020). Role and mechanism of angiotensin-converting enzyme 2 in acute lung injury in coronavirus disease 2019. Chronic Diseases and Translational Medicine, 6(2), 98-105.

28. Global health 50/50. (2020). [online] COVID-19 sex-disaggregated data tracker. Available at: https://globalhealth5050.org/ covid19/sex-disaggregated-data-tracker/ [Accessed 08 July 2020].

29. Gao, K., Shi, X., \& Wang, W. (2017). The life-course impact of smoking on hypertension, myocardial infarction and respiratory diseases. Scientific Reports, 7(1), 4330-4336.

30. Qiu, F., Liang, C. L., Liu, H., Zeng, Y. Q., Hou, S., Huang, S., Lai, X., \& Dai, Z. (2017). Impacts of cigarette smoking on immune responsiveness: Up and down or upside down? Oncotarget, 8(1), 268-284.

31. Jiang, C., Chen, Q., \& Xie, M. (2020). Smoking increases the risk of infectious diseases: A narrative review. Tobacco Induced Diseases, 18, 60 .

32. Zhou, G., Liu, H., He, M., Yue, M., Gong, P., Wu, F., Li, X., Pang, Y., Yang, X., Ma, J., Liu, M., Li, J., \& Zhang, X. (2018). Smoking, leisure-time exercise and frequency of self-reported common cold among the general population in northeastern China: A cross-sectional study. BMC Public Health, 18(1), 294.

33. Lee, J. S., Ki, S. Y., Hwang, I. S., Park, S. G., Kim, L., Chung, M. H., Cheong, H. J., \& Kim, W. J. (2010). Effect of smoking on influenza illness and vaccine-induced immune response in mice. Infection \& Chemotherapy, 42(6), 391-396.

34. Park, J. K., Lee, S., Lee, J. E., Han, K. D., Kim, J. H., Yoon, J. H., Park, S. W., Kim, Y. H., \& Cho, K. H. (2018). The association between smoking status and influenza vaccination coverage rate in Korean adults: Analysis of the 2010-2012 Korea National Health and nutrition examination survey. Korean Journal of Family Medicine, 39(2), 90-95.

35. Lawrence, H., Hunter, A., Murray, R., Lim, W. S., \& McKeever, T. (2019). Cigarette smoking and the occurrence of influenza systematic review. The Journal of Infection, 79(5), 401-406.

36. Çörtük, M., Acat, M., Yazici, O., Yasar, Z., Kiraz, K., Ataman, S. Y., Tanriverdi, E., Zitouni, B., Kirakli, C., Ediboglu, O., Tuksavul, F., Dirican, A., Celik, H. K., Ozkaya, S., \& Cetinkaya, E. (2017). Retrospective review of epidemic viral pneumonia cases in Turkey: A multicenter study. Experimental and Therapeutic Medicine, 13(4), 1431-1437.

37. Bleibtreu, A., Bertine, M., Bertin, C., Houhou-Fidouh, N., \& Visseaux, B. (2020). Focus on Middle East respiratory syndrome 
coronavirus (MERS-CoV). Medecine et Maladies Infectieuses, 50(3), 243-251.

38. Smith, J. C., Sausville, E. L., Girish, V., Yuan, M. L., Vasudevan, A., John, K. M., \& Sheltzer, J. M. (2020). Cigarette smoke exposure and inflammatory signaling increase the expression of the SARS-CoV-2 receptor ACE2 in the respiratory tract. Developmental Cell, 53(5), 514-529.e3.

39. Guan, W. J., Ni, Z. Y., Hu, Y., Liang, W. H., Ou, C. Q., He, J. X., Liu, L., Shan, H., Lei, C. L., Hui, D., Du, B., Li, L. J., Zeng, G., Yuen, K. Y., Chen, R. C., Tang, C. L., Wang, T., Chen, P. Y., Xiang, J., Li, S. Y., et al. (2020). Clinical characteristics of coronavirus disease 2019 in China. The New England Journal of Medicine, 382(18), 1708-1720.

40. Vardavas, C. I., \& Nikitara, K. (2020). COVID-19 and smoking: A systematic review of the evidence. Tobacco Induced Diseases, $18,20$.

41. Hannah R \& and Max R (2013) - [online] "Smoking". Published online at OurWorldInData.org. Available at: 'https:// ourworldindata.org/smoking. Accessed 6 July 2020.

42. Mizgerd, J. P. (2006). Lung infection-a public health priority. PLoS Medicine, 3(2), e76.

43. Klein, S. L., \& Flanagan, K. L. (2016). Sex differences in immune responses. Nature Reviews Immunology, 16(10), 626-638.

44. Ghosh, S., \& Klein, R. S. (2017). Sex drives dimorphic immune responses to viral infections. Journal of Immunology (Baltimore, Md. : 1950), 198(5), 1782-1790.

45. Bereshchenko, O., Bruscoli, S., \& Riccardi, C. (2018). Glucocorticoids, sex hormones, and immunity. Frontiers in Immunology, 9, 1332.

46. Bouman, A., Heineman, M. J., \& Faas, M. M. (2005). Sex hormones and the immune response in humans. Human Reproduction Update, 11(4), 411-423.

47. Kaufman, J. M., \& Vermeulen, A. (2005). The decline of androgen levels in elderly men and its clinical and therapeutic implications. Endocrine Reviews, 26(6), 833-876.

48. Ecochard, R., Bouchard, T., Leiva, R., Abdulla, S., Dupuis, O., Duterque, O., Garmier Billard, M., Boehringer, H., \& Genolini, C. (2017). Characterization of hormonal profiles during the luteal phase in regularly menstruating women. Fertility and Sterility, 108(1), 175-182.e1.

49. Markle, J. G., \& Fish, E. N. (2014). SeXX matters in immunity. Trends in Immunology, 35(3), 97-104.

50. Furman, D., Hejblum, B. P., Simon, N., Jojic, V., Dekker, C. L., Thiébaut, R., Tibshirani, R. J., \& Davis, M. M. (2014). Systems analysis of sex differences reveals an immunosuppressive role for testosterone in the response to influenza vaccination. Proceedings of the National Academy of Sciences of the United States of America, 111(2), 869-874.

51. Wichmann, M. W., Zellweger, R., DeMaso, C. M., Ayala, A., \& Chaudry, I. H. (1996). Mechanism of immunosuppression in males following trauma-hemorrhage. Critical role of testosterone. Archives of Surgery, 131(11), 1186-1192.

52. Bianchi, V. E. (2018). The anti-inflammatory effects of testosterone. Journal of the Endocrine Society, 3(1), 91-107.

53. Gold, S. M., \& Voskuhl, R. R. (2009). Estrogen and testosterone therapies in multiple sclerosis. Progress in Brain Research, 175, 239-251.

54. Bouman, A., Schipper, M., Heineman, M. J., \& Faas, M. M. (2004). Gender difference in the non-specific and specific immune response in humans. American Journal of Reproductive Immunology (New York, N.Y. : 1989), 52(1), 19-26.

55. Giltay, E. J., Fonk, J. C., von Blomberg, B. M., Drexhage, H. A., Schalkwijk, C., \& Gooren, L. J. (2000). In vivo effects of sex steroids on lymphocyte responsiveness and immunoglobulin levels in humans. The Journal of Clinical Endocrinology and Metabolism, 85(4), 1648-1657.
56. McMurray, R. W., Suwannaroj, S., Ndebele, K., \& Jenkins, J. K. (2001). Differential effects of sex steroids on T and B cells: Modulation of cell cycle phase distribution, apoptosis and bcl-2 protein levels. Pathobiology, 69(1), 44-58.

57. Folstad, I., \& Karter, A. J. (1992). Parasites, bright males, and the immunocompetence handicap. American Naturalist, 139(3), 603622.

58. Foo, Y. Z., Nakagawa, S., Rhodes, G., \& Simmons, L. W. (2017). The effects of sex hormones on immune function: A meta-analysis. Biological Reviews, 92(1), 551-571.

59. Hepworth, M. R., Hardman, M. J., \& Grencis, R. K. (2010). The role of sex hormones in the development of Th2 immunity in a gender-biased model of Trichuris muris infection. European Journal of Immunology, 40(2), 406-416.

60. Kissick, H. T., Sanda, M. G., Dunn, L. K., Pellegrini, K. L., On, S. T., Noel, J. K., \& Arredouani, M. S. (2014). Androgens alter Tcell immunity by inhibiting T-helper 1 differentiation. Proceedings of the National Academy of Sciences of the United States of America, 111(27), 9887-9892.

61. Zeng, F., Dai, C., Cai, P., Wang, J., Xu, L., Li, J., Hu, G., Wang, Z., Zheng, F., \& Wang, L. (2020). A comparison study of SARSCoV-2 IgG antibody between male and female COVID-19 patients: A possible reason underlying different outcome between sex. Journal of Medical Virology, 92, 2050-2054. https://doi. org/10.1002/jmv.25989.

62. Koh, Y. T., Gray, A., Higgins, S. A., Hubby, B., \& Kast, W. M. (2009). Androgen ablation augments prostate cancer vaccine immunogenicity only when applied after immunization. Prostate, 69(6), 571-584.

63. Kelly, D. M., Sellers, D. J., Woodroofe, M. N., Jones, T. H., \& Channer, K. S. (2013). Effect of testosterone on inflammatory markers in the development of early Atherogenesis in the testicular-feminized mouse model. Endocrine Research, 38(3), $125-138$.

64. Mohamad, N. V., Wong, S. K., Wan Hasan, W. N., Jolly, J. J., Nur-Farhana, M. F., Ima-Nirwana, S., \& Chin, K. Y. (2019). The relationship between circulating testosterone and inflammatory cytokines in men. The Aging Male, 22(2), 129-140.

65. Roved, J., Westerdahl, H., \& Hasselquist, D. (2017). Sex differences in immune responses: Hormonal effects, antagonistic selection, and evolutionary consequences. Hormones and Behavior, $88,95-105$.

66. Wu, F. C., Tajar, A., Pye, S. R., Silman, A. J., Finn, J. D., O'Neill, T. W., Bartfai, G., Casanueva, F., Forti, G., Giwercman, A., Huhtaniemi, I. T., Kula, K., Punab, M., Boonen, S., Vanderschueren, D., \& European Male Aging Study Group. (2008). Hypothalamic-pituitary-testicular axis disruptions in older men are differentially linked to age and modifiable risk factors: The European male aging study. The Journal of Clinical Endocrinology and Metabolism, 93(7), 2737-2745.

67. Snyder, P. J., Bhasin, S., Cunningham, G. R., Matsumoto, A. M., Stephens-Shields, A. J., Cauley, J. A., Gill, T. M., Barrett-Connor, E., Swerdloff, R. S., Wang, C., Ensrud, K. E., Lewis, C. E., Farrar, J. T., Cella, D., Rosen, R. C., Pahor, M., Crandall, J. P., Molitch, M. E., Cifelli, D., Dougar, D., et al. (2016). Effects of testosterone treatment in older men. The New England Journal of Medicine, 374(7), 611-624.

68. Wang, C., Jackson, G., Jones, T. H., Matsumoto, A. M., Nehra, A., Perelman, M. A., Swerdloff, R. S., Traish, A., Zitzmann, M., \& Cunningham, G. (2011). Low testosterone associated with obesity and the metabolic syndrome contributes to sexual dysfunction and cardiovascular disease risk in men with type 2 diabetes. Diabetes Care, 34(7), 1669-1675.

69. Bhasin, S., Brito, J. P., Cunningham, G. R., Hayes, F. J., Hodis, H. N., Matsumoto, A. M., Snyder, P. J., Swerdloff, R. S., Wu, F. C., \& Yialamas, M. A. (2018). Testosterone therapy in men with 
Hypogonadism: An Endocrine Society clinical practice guideline. The Journal of Clinical Endocrinology and Metabolism, 103(5), 1715-1744.

70. Maggio, M., Basaria, S., Ceda, G. P., Ble, A., Ling, S. M., Bandinelli, S., Valenti, G., \& Ferrucci, L. (2005). The relationship between testosterone and molecular markers of inflammation in older men. Journal of Endocrinological Investigation, 28(11 Suppl proceedings), 116-119.

71. Schroeder, M., Tuku, B., Jarczak, D., Nierhaus, A., Bai, T., Jacobsen, H., ... \& Aberle, J. (2020). The majority of male patients with COVID-19 present low testosterone levels on admission to Intensive Care in Hamburg, Germany: a retrospective cohort study. medRxiv. 2020.05.07.20073817.

72. Jin, J. M., Bai, P., He, W., Wu, F., Liu, X. F., Han, D. M., Liu, S., \& Yang, J. K. (2020). Gender differences in patients with COVID19: Focus on severity and mortality. Frontiers in Public Health, 8 , 152.

73. Jordan, R. E., Adab, P., \& Cheng, K. K. (2020). Covid-19: Risk factors for severe disease and death. BMJ (Clinical research ed.), $368, \mathrm{~m} 1198$.

74. Goren, A., Vaño-Galván, S., Wambier, C. G., McCoy, J., GomezZubiaur, A., Moreno-Arrones, O. M., Shapiro, J., Sinclair, R. D., Gold, M. H., Kovacevic, M., Mesinkovska, N. A., Goldust, M., \& Washenik, K. (2020). A preliminary observation: Male pattern hair loss among hospitalized COVID-19 patients in Spain - a potential clue to the role of androgens in COVID-19 severity. Journal of Cosmetic Dermatology, 19(7), 1545-1547.

75. Lin, B., Ferguson, C., White, J. T., Wang, S., Vessella, R., True, L. D., Hood, L., \& Nelson, P. S. (1999). Prostate-localized and androgen-regulated expression of the membrane-bound serine protease TMPRSS2. Cancer Research, 59(17), 4180-4184.

76. Mikkonen, L., Pihlajamaa, P., Sahu, B., Zhang, F. P., \& Jänne, O. A. (2010). Androgen receptor and androgen-dependent gene expression in lung. Molecular and Cellular Endocrinology, 317(12), 14-24

77. Wambier, C. G., \& Goren, A. (2020). Severe acute respiratory syndrome coronavirus 2 (SARS-CoV-2) infection is likely to be androgen mediated. Journal of the American Academy of Dermatology, 83(1), 308-309.

78. Shen, L. W., Mao, H. J., Wu, Y. L., Tanaka, Y., \& Zhang, W. (2017). TMPRSS2: A potential target for treatment of influenza virus and coronavirus infections. Biochimie, 142, 1-10.

79. Lau, E. H., Hsiung, C. A., Cowling, B. J., Chen, C. H., Ho, L. M., Tsang, T., Chang, C. W., Donnelly, C. A., \& Leung, G. M. (2010). A comparative epidemiologic analysis of SARS in Hong Kong, Beijing and Taiwan. BMC Infectious Diseases, 10, 50.

80. Assiri, A., Al-Tawfiq, J. A., Al-Rabeeah, A. A., Al-Rabiah, F. A., Al-Hajjar, S., Al-Barrak, A., Flemban, H., Al-Nassir, W. N., Balkhy, H. H., Al-Hakeem, R. F., Makhdoom, H. Q., Zumla, A. I., \& Memish, Z. A. (2013). Epidemiological, demographic, and clinical characteristics of 47 cases of Middle East respiratory syndrome coronavirus disease from Saudi Arabia: A descriptive study. The Lancet. Infectious Diseases, 13(9), 752-761.

81. Wang, C., Yu, H., Horby, P. W., Cao, B., Wu, P., Yang, S., Gao, H., Li, H., Tsang, T. K., Liao, Q., Gao, Z., Ip, D. K., Jia, H., Jiang, H., Liu, B., Ni, M. Y., Dai, X., Liu, F., Van Kinh, N., Liem, N. T., et al. (2014). Comparison of patients hospitalized with influenza a subtypes H7N9, H5N1, and 2009 pandemic H1N1. Clinical Infectious Diseases, 58(8), 1095-1103.

82. Ling, L. M., Chow, A. L., Lye, D. C., Tan, A. S., Krishnan, P., Cui, L., Win, N. N., Chan, M., Lim, P. L., Lee, C. C., \& Leo, Y. S. (2010). Effects of early oseltamivir therapy on viral shedding in 2009 pandemic influenza a (H1N1) virus infection. Clinical Infectious Diseases, 50(7), 963-969.
83. Nicola, W. G., Khayria, M. I., \& Osfor, M. M. (1997). Plasma testosterone level and the male genital system after chloroquine therapy. Bollettino Chimico Farmaceutico, 136(1), 39-43.

84. Taneja, V. (2018). Sex Hormones Determine Immune Response. Frontiers in Immunology, 9, 1931.

85. Cutolo, M., Capellino, S., Sulli, A., Serioli, B., Secchi, M. E., Villaggio, B., \& Straub, R. H. (2006). Estrogens and autoimmune diseases. Annals of the New York Academy of Sciences, 1089 , 538-547.

86. Grimaldi, C. M., Jeganathan, V., \& Diamond, B. (2006). Hormonal regulation of B cell development: 17ß-estradiol impairs negative selection of high-affinity DNA-reactive B cells at more than one developmental checkpoint. The Journal of Immunology, 176(5), 2703-2710.

87. Klein, S. L. (2000). The effects of hormones on sex differences in infection: From genes to behavior. Neuroscience and Biobehavioral Reviews, 24(6), 627-638.

88. Mo, R., Chen, J., Grolleau-Julius, A., Murphy, H. S., Richardson, B. C., \& Yung, R. L. (2005). Estrogen regulates CCR gene expression and function in $\mathrm{T}$ lymphocytes. The Journal of Immunology, 174(10), 6023-6029.

89. Törnwall, J., Carey, A. B., Fox, R. I., \& Fox, H. S. (1999). Estrogen in autoimmunity: Expression of estrogen receptors in thymic and autoimmune T cells. The Journal of Gender-specific Medicine: JGSM: The Official Journal of the Partnership for Women's Health at Columbia, 2(5), 33-40.

90. Kovats, S. (2015). Estrogen receptors regulate innate immune cells and signaling pathways. Cellular Immunology, 294(2), 6369 .

91. Cunningham, M., \& Gilkeson, G. (2011). Estrogen receptors in immunity and autoimmunity. Clinical Reviews in Allergy \& Immunology, 40(1), 66-73.

92. Shen, H., Panchanathan, R., Rajavelu, P., Duan, X., Gould, K. A., \& Choubey, D. (2010). Gender-dependent expression of murine Irf5 gene: Implications for sex bias in autoimmunity. Journal of Molecular Cell Biology, 2(5), 284-290.

93. Panchanathan, R., Liu, H., \& Choubey, D. (2013). Expression of murine Unc93b1 is up-regulated by interferon and estrogen signaling: Implications for sex bias in the development of autoimmunity. International Immunology, 25(9), 521-529.

94. Panchanathan, R., Shen, H., Bupp, M. G., Gould, K. A., \& Choubey, D. (2009). Female and male sex hormones differentially regulate expression of Ifi202, an interferon-inducible lupus susceptibility gene within the Nba2 interval. The Journal of Immunology, 183(11), 7031-7038.

95. Sabo-Attwood, T., Kroll, K. J., \& Denslow, N. D. (2004). Differential expression of largemouth bass (Micropterus salmoides) estrogen receptor isotypes alpha, beta, and gamma by estradiol. Molecular and Cellular Endocrinology, 218(1-2), 107-118.

96. Schlenker, E. H., \& Hansen, S. N. (2006). Sex-specific densities of estrogen receptors alpha and beta in the subnuclei of the nucleus tractus solitarius, hypoglossal nucleus and dorsal vagal motor nucleus weanling rats. Brain Research, 1123(1), 89-100.

97. Faas, M., Bouman, A., Moesa, H., Heineman, M. J., De Leij, L., \& Schuiling, G. (2000). The immune response during the luteal phase of the ovarian cycle: A Th2-type response? Fertility and Sterility, 74(5), 1008-1013.

98. Karpuzoglu, E., Phillips, R. A., Gogal Jr., R. M., \& Ansar Ahmed, S. (2007). IFN-gamma-inducing transcription factor, T-bet is upregulated by estrogen in murine splenocytes: Role of IL-27 but not IL-12. Molecular Immunology, 44(7), 1808-1814.

99. Mauvais-Jarvis, F., Klein, S. L., \& Levin, E. R. (2020). Estradiol, progesterone, immunomodulation, and COVID-19 outcomes. Endocrinology, 161(9), bqaa127. 
100. Tang, Y., Liu, J., Zhang, D., Xu, Z., Ji, J., \& Wen, C. (2020). Cytokine storm in COVID-19: The current evidence and treatment strategies. Frontiers in Immunology, 11, 1708.

101. Channappanavar, R., Fett, C., Mack, M., Ten Eyck, P. P., Meyerholz, D. K., \& Perlman, S. (2017). Sex-based differences in susceptibility to severe acute respiratory syndrome coronavirus infection. Journal of Immunology, 198(10), 4046-4053.

102. Quakkelaar, E. D., \& Melief, C. J. (2012). Experience with synthetic vaccines for cancer and persistent virus infections in nonhuman primates and patients. Advances in Immunology, 114, 77106.

103. Schurz, H., Salie, M., Tromp, G., Hoal, E. G., Kinnear, C. J., \& Möller, M. (2019). The X chromosome and sex-specific effects in infectious disease susceptibility. Human Genomics, 13(1), 2.

104. Barakat, T. S., \& Gribnau, J. (2012). X chromosome inactivation in the cycle of life. Development, 139(12), 2085-2089.

105. Eggan, K., Akutsu, H., Hochedlinger, K., Rideout, W., Yanagimachi, R., \& Jaenisch, R. (2000). X-chromosome inactivation in cloned mouse embryos. Science, 290(5496), 15781581.

106. Carrel, L., \& Willard, H. F. (2005). X-inactivation profile reveals extensive variability in $\mathrm{X}$-linked gene expression in females. Nature, 434(7031), 400-404.

107. Libert, C., Dejager, L., \& Pinheiro, I. (2010). The X chromosome in immune functions: When a chromosome makes the difference. Nature Reviews Immunology, 10(8), 594-604.

108. Ito, T., Wang, Y. H., \& Liu, Y. J. (2005). Plasmacytoid dendritic cell precursors/type I interferon-producing cells sense viral infection by toll-like receptor (TLR) 7 and TLR9. Springer Seminars in Immunopathology, 26(3), 221-229.

109. Hammadi, A., Billard, C., Faussat, A. M., \& Kolb, J. P. (2008). Stimulation of iNOS expression and apoptosis resistance in B-cell chronic lymphocytic leukemia (B-CLL) cells through engagement of toll-like receptor 7 (TLR-7) and NF-KB activation. Nitric Oxide, 19(2), 138-145.

110. Souyris, M., Cenac, C., Azar, P., Daviaud, D., Canivet, A., Grunenwald, S., Pienkowski, C., Chaumeil, J., Mejía, J. E., \& Guéry, J. C. (2018). TLR7 escapes X chromosome inactivation in immune cells. Science Immunology, 3(19), eaap8855.

111. Kwaa, A. K., Talana, C. A., \& Blankson, J. N. (2019). Interferon alpha enhances NK cell function and the suppressive capacity of HIV-specific CD8+ T cells. Journal of Virology, 93(3), e01541e01518.

112. Conti, P., Ronconi, G., Caraffa, A., Gallenga, C. E., Ross, R., Frydas, I., \& Kritas, S. K. (2020). Induction of pro-inflammatory cytokines (IL-1 and IL-6) and lung inflammation by Coronavirus19 (COVI-19 or SARS-CoV-2): Anti-inflammatory strategies. Journal of Biological Regulators and Homeostatic Agents, 34(2), 1 Advance online publication.

113. Conti, P., \& Younes, A. (2020). Coronavirus COV-19/SARSCoV-2 affects women less than men: Clinical response to viral infection. Journal of Biological Regulators and Homeostatic Agents, 34(2). https://doi.org/10.23812/Editorial-Conti-3 Advance online publication.

114. Seki, M., Kohno, S., Newstead, M. W., Zeng, X., Bhan, U., Lukacs, N. W., Kunkel, S. L., \& Standiford, T. J. (2010). Critical role of IL-1 receptor-associated kinase-M in regulating chemokine-dependent deleterious inflammation in murine influenza pneumonia. Journal of Immunology (Baltimore, Md. : 1950), 184(3), 1410-1418.

115. Huang, C., Wang, Y., Li, X., Ren, L., Zhao, J., Hu, Y., Zhang, L., Fan, G., Xu, J., Gu, X., Cheng, Z., Yu, T., Xia, J., Wei, Y., Wu, W., Xie, X., Yin, W., Li, H., Liu, M., Xiao, Y., Gao, H., Guo, L., Xie, J., Wang, G., Jiang, R., Gao, Z., Jin, Q., Wang, J., \& Cao, B. (2020). Clinical features of patients infected with 2019 novel coronavirus in Wuhan, China. Lancet (London, England), 395(10223), 497-506.

116. Nguyen, L. T., Ramanathan, M., Weinstock-Guttman, B., Baier, M., Brownscheidle, C., \& Jacobs, L. D. (2003). Sex differences in in vitro pro-inflammatory cytokine production from peripheral blood of multiple sclerosis patients. Journal of the Neurological Sciences, 209(1-2), 93-99.

117. Wei, X., Xiao, Y. T., Wang, J., Chen, R., Zhang, W., Yang, Y., ... \& Chen, W. (2020). Sex differences in severity and mortality among patients with COVID-19: evidence from pooled literature analysis and insights from integrated bioinformatic analysis. arXiv preprint arXiv:2003.13547.

118. Hudspeth, K., Fogli, M., Correia, D. V., Mikulak, J., Roberto, A., Della Bella, S., Silva-Santos, B., \& Mavilio, D. (2012). Engagement of NKp30 on V $81 \mathrm{~T}$ cells induces the production of CCL3, CCL4, and CCL5 and suppresses HIV-1 replication. Blood, 119(17), 4013-4016.

119. Kvetnanský, R., Pacák, K., Fukuhara, K., Viskupic, E., Hiremagalur, B., Nankova, B., Goldstein, D. S., Sabban, E. L., \& Kopin, I. J. (1995). Sympathoadrenal system in stress. Interaction with the hypothalamic-pituitary-adrenocortical system. Annals of the New York Academy of Sciences, 771, 131-158.

120. Mattioli, A. V., Nasi, M., Cocchi, C., \& Farinetti, A. (2020). COVID-19 outbreak: Impact of the quarantine-induced stress on cardiovascular disease risk burden. Future Cardiology. https://doi. org/10.2217/fca-2020-0055.

121. Barel, E., Abu-Shkara, R., Colodner, R., Masalha, R., Mahagna, L., Zemel, O. C., \& Cohen, A. (2018). Gonadal hormones modulate the HPA-axis and the SNS in response to psychosocial stress. Journal of Neuroscience Research, 96(8), 1388-1397.

122. Bale, T. L., \& Epperson, C. N. (2015). Sex differences and stress across the lifespan. Nature Neuroscience, 18(10), 1413-1420.

123. Oyola, M. G., \& Handa, R. J. (2017). Hypothalamic-pituitaryadrenal and hypothalamic-pituitary-gonadal axes: Sex differences in regulation of stress responsivity. Stress (Amsterdam, Netherlands), 20(5), 476-494.

124. Mariniello, K., Ruiz-Babot, G., McGaugh, E. C., Nicholson, J. G., Gualtieri, A., Gaston-Massuet, C., Nostro, M. C., \& Guasti, L. (2019). Stem cells, self-renewal, and lineage commitment in the endocrine system. Frontiers in Endocrinology, 10, 772.

125. Steenblock, C., Rubin de Celis, M. F., Delgadillo Silva, L. F., Pawolski, V., Brennand, A., Werdermann, M., Berger, I., Santambrogio, A., Peitzsch, M., Andoniadou, C. L., Schally, A. V., \& Bornstein, S. R. (2018). Isolation and characterization of adrenocortical progenitors involved in the adaptation to stress. Proceedings of the National Academy of Sciences of the United States of America, 115(51), 12997-13002.

126. Grabek, A., Dolfi, B., Klein, B., Jian-Motamedi, F., Chaboissier, M. C., \& Schedl, A. (2019). The adult adrenal cortex undergoes rapid tissue renewal in a sex-specific manner. Cell Stem Cell, 25(2), 290-296.e2.

127. De Wit, E., Van Doremalen, N., Falzarano, D., \& Munster, V. J. (2016). SARS and MERS: Recent insights into emerging coronaviruses. Nature Reviews Microbiology, 14(8), 523-534.

128. WHO SARS (Severe Acute Respiratory Syndrome). Accessed on 9th July 2020. Retrieved from https://www.who.int/ith/diseases/ sars/en/

129. Karlberg, J., Chong, D. S., \& Lai, W. Y. (2004). Do men have a higher case fatality rate of severe acute respiratory syndrome than women do? American Journal of Epidemiology, 159(3), 229-231.

130. Alghamdi, I. G., Hussain, I. I., Almalki, S. S., Alghamdi, M. S., Alghamdi, M. M., \& El-Sheemy, M. A. (2014). The pattern of Middle East respiratory syndrome coronavirus in Saudi Arabia: A descriptive epidemiological analysis of data from the Saudi Ministry of Health. International Journal of General Medicine, 7, 417-423. 
131. Choi, W. S., Kang, C. I., Kim, Y., Choi, J. P., Joh, J. S., Shin, H. S., Kim, G., Peck, K. R., Chung, D. R., Kim, H. O., Song, S. H., Kim, Y. R., Sohn, K. M., Jung, Y., Bang, J. H., Kim, N. J., Lee, K. S., Jeong, H. W., Rhee, J. Y., Kim, E. S., et al. (2016). Clinical presentation and outcomes of Middle East respiratory syndrome in the Republic of Korea. Infection Chemotherapy, 48(2), 118-126.

132. Bose, S., Adapa, S., Aeddula, N. R., Roy, S., Nandikanti, D., Vupadhyayula, P. M., Naramala, S., Gayam, V., Muppidi, V., \& Konala, V. M. (2020). Medical management of COVID-19: Evidence and experience. Journal of Clinical Medicine Research, 12(6), 329-343.

133. Gautret, P., Lagier, J. C., Parola, P., Hoang, V. T., Meddeb, L., Mailhe, M., Doudier, B., Courjon, J., Giordanengo, V., Vieira, V. E., Tissot Dupont, H., Honoré, S., Colson, P., Chabrière, E., La Scola, B., Rolain, J. M., Brouqui, P., \& Raoult, D. (2020). Hydroxychloroquine and azithromycin as a treatment of COVID-19: Results of an open-label non-randomized clinical trial. International Journal of Antimicrobial Agents, 56(1), 105949.

134. Food and Drug Administration. https://www.fda.gov/media/ 137564/download.

135. Sanders, J. M., Monogue, M. L., Jodlowski, T. Z., \& Cutrell, J. B. (2020). Pharmacologic treatments for coronavirus disease 2019 (COVID-19): A review. JAMA, https://doi.org/10.1001/jama. 2020.6019. Advance online publication.

136. Cao, B., Wang, Y., Wen, D., Liu, W., Wang, J., Fan, G., Ruan, L., Song, B., Cai, Y., Wei, M., Li, X., Xia, J., Chen, N., Xiang, J., Yu, T., Bai, T., Xie, X., Zhang, L., Li, C., Yuan, Y., Chen, H., Li, H., Huang, H., Tu, S., Gong, F., Liu, Y., Wei, Y., Dong, C., Zhou, F., Gu, X., Xu, J., Liu, Z., Zhang, Y., Li, H., Shang, L., Wang, K., Li, K., Zhou, X., Dong, X., Qu, Z., Lu, S., Hu, X., Ruan, S., Luo, S., Wu, J., Peng, L., Cheng, F., Pan, L., Zou, J., Jia, C., Wang, J., Liu, X., Wang, S., Wu, X., Ge, Q., He, J., Zhan, H., Qiu, F., Guo, L., Huang, C., Jaki, T., Hayden, F. G., Horby, P. W., Zhang, D., \& Wang, C. (2020). A trial of Lopinavir-ritonavir in adults hospitalized with severe Covid-19. The New England Journal of Medicine, 382(19), 1787-1799.

137. Atal, S., \& Fatima, Z. (2020). IL-6 inhibitors in the treatment of serious COVID-19: A promising therapy?. Pharmaceutical Medicine, 1-9. Advance online publication.

138. Hermankova, B., Kossl, J., Bohacova, P., Javorkova, E., Hajkova, M., Krulova, M., Zajicova, A., \& Holan, V. (2019). The Immunomodulatory potential of Mesenchymal stem cells in a retinal inflammatory environment. Stem Cell Reviews and Reports, 15(6), 880-891.

139. Rühle, A., Lopez Perez, R., Zou, B., Grosu, A. L., Huber, P. E., \& Nicolay, N. H. (2019). The therapeutic potential of Mesenchymal stromal cells in the treatment of chemotherapy-induced tissue damage. Stem Cell Reviews and Reports, 15(3), 356-373.

140. Filho, D. M., de Carvalho Ribeiro, P., Oliveira, L. F., Dos Santos, A., Parreira, R. C., Pinto, M., \& Resende, R. R. (2019). Enhancing the therapeutic potential of Mesenchymal stem cells with the CRISPR-Cas system. Stem Cell Reviews and Reports, 15(4), 463-473.

141. Halim, N., Ch'ng, E. S., Kardia, E., Ali, S. A., Radzi, R., \& Yahaya, B. H. (2019). Aerosolised Mesenchymal stem cells expressing Angiopoietin-1 enhances airway repair. Stem Cell Reviews and Reports, 15(1), 112-125.
142. Golchin, A., Seyedjafari, E., \& Ardeshirylajimi, A. (2020). Mesenchymal stem cell therapy for COVID-19: Present or future. Stem Cell Reviews and Reports, 16(3), 427-433.

143. Li, Y., Xu, J., Shi, W., Chen, C., Shao, Y., Zhu, L., Lu, W., \& Han, X. (2016). Mesenchymal stromal cell treatment prevents H9N2 avian influenza virus-induced acute lung injury in mice. Stem Cell Research \& Therapy, 7(1), 159.

144. Chan, M. C., Kuok, D. I., Leung, C. Y., Hui, K. P., Valkenburg, S. A., Lau, E. H., Nicholls, J. M., Fang, X., Guan, Y., Lee, J. W., Chan, R. W., Webster, R. G., Matthay, M. A., \& Peiris, J. S. (2016). Human mesenchymal stromal cells reduce influenza a H5N1-associated acute lung injury in vitro and in vivo. Proceedings of the National Academy of Sciences of the United States of America, 113(13), 3621-3626.

145. Khatri, M., Richardson, L. A., \& Meulia, T. (2018). Mesenchymal stem cell-derived extracellular vesicles attenuate influenza virusinduced acute lung injury in a pig model. Stem Cell Research \& Therapy, 9(1), 17.

146. Liang, B., Chen, J., Li, T., Wu, H., Yang, W., Li, Y., et al. (2020). Clinical remission of a critically ill COVID-19 patient treated by human umbilical cord mesenchymal stem cells. ChinaXiv, 2, v1.

147. Leng, Z., Zhu, R., Hou, W., Feng, Y., Yang, Y., Han, Q., Shan, G., Meng, F., Du, D., Wang, S., Fan, J., Wang, W., Deng, L., Shi, H., Li, H., Hu, Z., Zhang, F., Gao, J., Liu, H., Li, X., et al. (2020). Transplantation of ACE2 ${ }^{-}$Mesenchymal stem cells improves the outcome of patients with COVID-19 pneumonia. Aging and Disease, 11(2), 216-228.

148. Luke, T. C., Kilbane, E. M., Jackson, J. L., \& Hoffman, S. L. (2006). Meta-analysis: Convalescent blood products for Spanish influenza pneumonia: A future H5N1 treatment? Annals of Internal Medicine, 145(8), 599-609.

149. Zhang, J., Xie, B., \& Hashimoto, K. (2020). Current status of potential therapeutic candidates for the COVID-19 crisis. Brain, Behavior, and Immunity, 87, 59-73.

150. Chen, L., Xiong, J., Bao, L., \& Shi, Y. (2020). Convalescent plasma as a potential therapy for COVID-19. The Lancet Infectious Diseases, 20(4), 398-400.

151. Cheng, Y., Wong, R., Soo, Y. O., Wong, W. S., Lee, C. K., Ng, M. H., Chan, P., Wong, K. C., Leung, C. B., \& Cheng, G. (2005). Use of convalescent plasma therapy in SARS patients in Hong Kong. European Journal of Clinical Microbiology and Infectious Diseases, 24(1), 44-46.

152. Shen, C., Wang, Z., Zhao, F., Yang, Y., Li, J., Yuan, J., Wang, F., Li, D., Yang, M., Xing, L., Wei, J., Xiao, H., Yang, Y., Qu, J., Qing, L., Chen, L., Xu, Z., Peng, L., Li, Y., Zheng, H., Chen, F., Huang, K., Jiang, Y., Liu, D., Zhang, Z., Liu, Y., \& Liu, L. (2020). Treatment of 5 critically ill patients with COVID-19 with convalescent plasma. JAMA, 323(16), 1582-1589.

153. Jiang, S., Hillyer, C., \& Du, L. (2020). Neutralizing antibodies against SARS-CoV-2 and other human coronaviruses. Trends in Immunology, 41(5), 355-359.

Publisher's Note Springer Nature remains neutral with regard to jurisdictional claims in published maps and institutional affiliations. 